\title{
Development of cold-formed steel moment-resisting connections with bolting friction-slip mechanism for seismic applications
}

\author{
Marzie Shahini ${ }^{a}$, Alireza Bagheri Sabbagh a, ${ }^{*}$, Paul Davidson ${ }^{a}$, Rasoul Mirghaderib \\ a School of Engineering, King`s College, University of Aberdeen, Aberdeen, Scotland, UK \\ ${ }^{b}$ School of Civil Engineering, University of Tehran, Tehran, Iran
}

\begin{abstract}
This paper presents an investigation into a friction-slip mechanism in bolted joints in cold-formed steel (CFS) moment-resisting connections suitable for seismic areas. The aim is to achieve higher ductility and energy dissipation capacity through an appropriately designed bolted connection, enabling activation of bolt slip, acting as a fuse mechanism, postponing the initiation of non-ductile local buckling in the CFS beams. By means of validated finite element analysis (FEA), both monotonic and cyclic performance of CFS connections comprising two types of square (SB) and circular (CB) bolt group arrangements, with four types of beam sections, are studied comparatively without and with slip at various levels. It is shown that the connections with slip provide higher energy dissipation capacity by up to $75 \%$ compared with that of the connections without slip. A design approach to predict an appropriate level for the connection slip moments to be initiated before the beam buckling moment is introduced using the direct strength method (DSM). On comparing the bolt forces obtained for the $\mathrm{SB}$ and $\mathrm{CB}$ groups, the $\mathrm{CB}$ connections produce a more uniform bolt-group force distribution which is closer to the idealised method; while the SB connection encounter a significant delay of up to $30 \%$ in activation of bolt group slip which could lead to unfavourable beam local buckling. Furthermore, to avoid an unfavourable hardening effect due to the bolts bearing action, slotted holes are used with a recommended length obtained for the cyclic movements of the bolts in the range of the designed connections. The instantaneous centre of rotation results show that the connections with slip have less deviation from the idealised centre of rotation than the connections without slip.
\end{abstract}

Keywords: Cold-formed steel; friction -slip mechanism; seismic energy dissipation; momentresisting bolted connections; bolt-group force distribution. 


\section{Introduction}

Cold-formed steel (CFS) sections are typically made of thin-walled elements with relatively large width-to-thickness ratio which makes them vulnerable to premature local buckling before reaching yielding strength. Local buckling can not only significantly reduce strength, but for typical width-tothickness ratios can also cause rapid post buckling loss of capacity, which consequently reduces the stiffness and ductility capacity of CFS structures. As a result, this particularly limits their structural applications in seismic areas [1]. Furthermore, relatively low strength and stiffness of the joints of the conventional CFS stud-wall frame systems [2] highlights the need for improvements in CFS structures. In an attempt to address these drawbacks and to facilitate wider use of CFS structures, a CFS webbolted moment-resisting (MR) joint has been recently developed by the second author [3-6]. The design approach in this study was to increase local buckling resistance of CFS beams as the primary energy dissipative members. The previously developed joint comprises curved flange beam sections connected to the column using a through plate (TP) and transverse stiffeners (see Fig. 1 (a)). The developed connection meets the requirements for full strength/rigid joints according to EN 1993-1-8: 2005 [7] and high ductility class moment frames as per EN 1998-1: 2004 [8] and ANSI/AISC 341-05, 2005 [9].

In CFS structures, bolted connections can be designed to provide ductility and energy dissipation capacity through initial slippage and bearing action developed by Sato and Uang [10] which has been recommended for single-storey moment-resisting frames. Development of a bolted connection with a targeted design performance, however, requires addressing various types of uncertainties [11]. These include both physical and design deficiencies such as frictional coefficient, bolt pre-tension, positioning of bolts within their holes, instantaneous centre of rotation (ICR) and a precise force distribution within a bolt-group. All of which vary through loading increments, when a bolt-group undergoes different stages of friction, slip and bearing actions, which affect the design and momentrotation characteristics of a bolted connection [12]. These alter the bolt force distribution from that of the design with a rigid motion assumption in which the centre of rotation, in cases where shear force on the joint is insignificant, approximately coincides with the geometrical centre of the bolts [13, 14]. The variation of the centre of rotation was also noted during the previously tested web-bolted connections of $2 \mathrm{~m}$ length cantilever beams with shear force relatively small compared to the moment on the joint [3], due to which a non-uniform bearing elongation occurred in the bolt group (Fig. 1(b)). This can be identified comparing the bearing elongation of the $1^{\text {st }}$ and the $4^{\text {th }}$ lines of the bolts, as seen in Fig. 1 (b), indicating that the bolt-group centre of rotation was closer to the $1^{\text {st }}$ line towards the column side. 


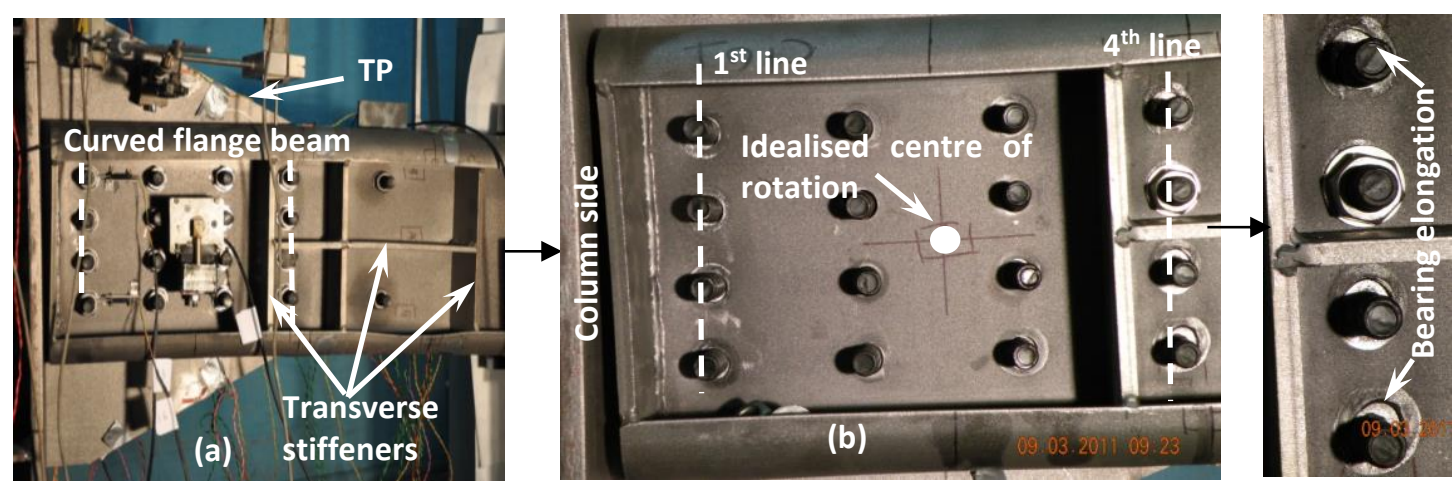

Figure 1. Developed web-bolted CFS connection with non-uniform bolt-group bearing elongation [3] This paper presents detailed FE investigation on a new configuration of CFS MR-connections, in which the design approach is to dissipate energy mainly through bolted connections rather than yielding in CFS beams. This incorporates a friction-slip mechanism into a slotted bolting type of connection aiming to postpone local buckling and to improve ductility and seismic energy dissipation capacities. Shu et al. [15] have recently developed a similar type of bolted connections for heavier hot-rolled steel structures, meeting Special Moment Frame seismic design requirements [9]. It was shown that higher ductility and energy dissipation capacities can be achieved through slotted connections compared with standard bolted connections.

Furthermore, in this paper, the bolt-group force distribution is obtained and discussed for two types of bolting arrangements using three section shapes of flat-flange, segmental-flange and curved-flange back-to-back channels. As such, more practical segmental flange beam sections are proposed as opposed to the curved flange beam sections which would require more complex manufacturing process. The outcome of the presented work has informed the design of experiments on the developed CFS connections, the full results of which will be reported subsequently. The computational methodology adopted herein is validated against these experiments for an example connection developing slip behaviour.

\section{Design considerations of the CFS beam-TP-column joint}

A single-sided $2.5 \mathrm{~m}$ length web bolted beam-TP-column joint (shown in Fig. 2) has been designed, representing the mid-span inflection point of a $5 \mathrm{~m}$ bay moment-resisting frame subjected to lateral loading. Two types of square (SB) and circular (CB) beam-to-TP bolting arrangements have been considered for comparison purposes. The choice of circular bolting has been examined due to a more uniform bending rotation predicted in the bolt group compared with the typical square bolting arrangement. Four types of beam cross sections with flat flange $(F)$, segmental flange with vertical lips (S), segmental flange with inclined lips $\left(\mathrm{S}^{*}\right)$ and curved flange (C), all illustrated in Fig. 2, have been 
used with a range of 200 and $300 \mathrm{~mm}$ web depth and 2, 4 and $6 \mathrm{~mm}$ thicknesses. The $300 \mathrm{~mm}$ deep beam is to accommodate a wider bolt pattern compared to the $200 \mathrm{~mm}$ deep section. The total flange width including the lips and the segmental parts are 125 or $150 \mathrm{~mm}$ for the 200 or $300 \mathrm{~mm}$ deep beams, respectively. The use of the same amount of steel for all types of the cross-sections for a given thickness is for the purpose of a comparative study between the results. All the sections can be manufactured using rolling machines or press brakes. Fig. 2 also includes some sequential steps from start to final bends of shaping a curved flange beam, which is deemed to be a complex CFS section, using a press brake. To avoid touching the flange edge during the bending process a curved press head was utilised.

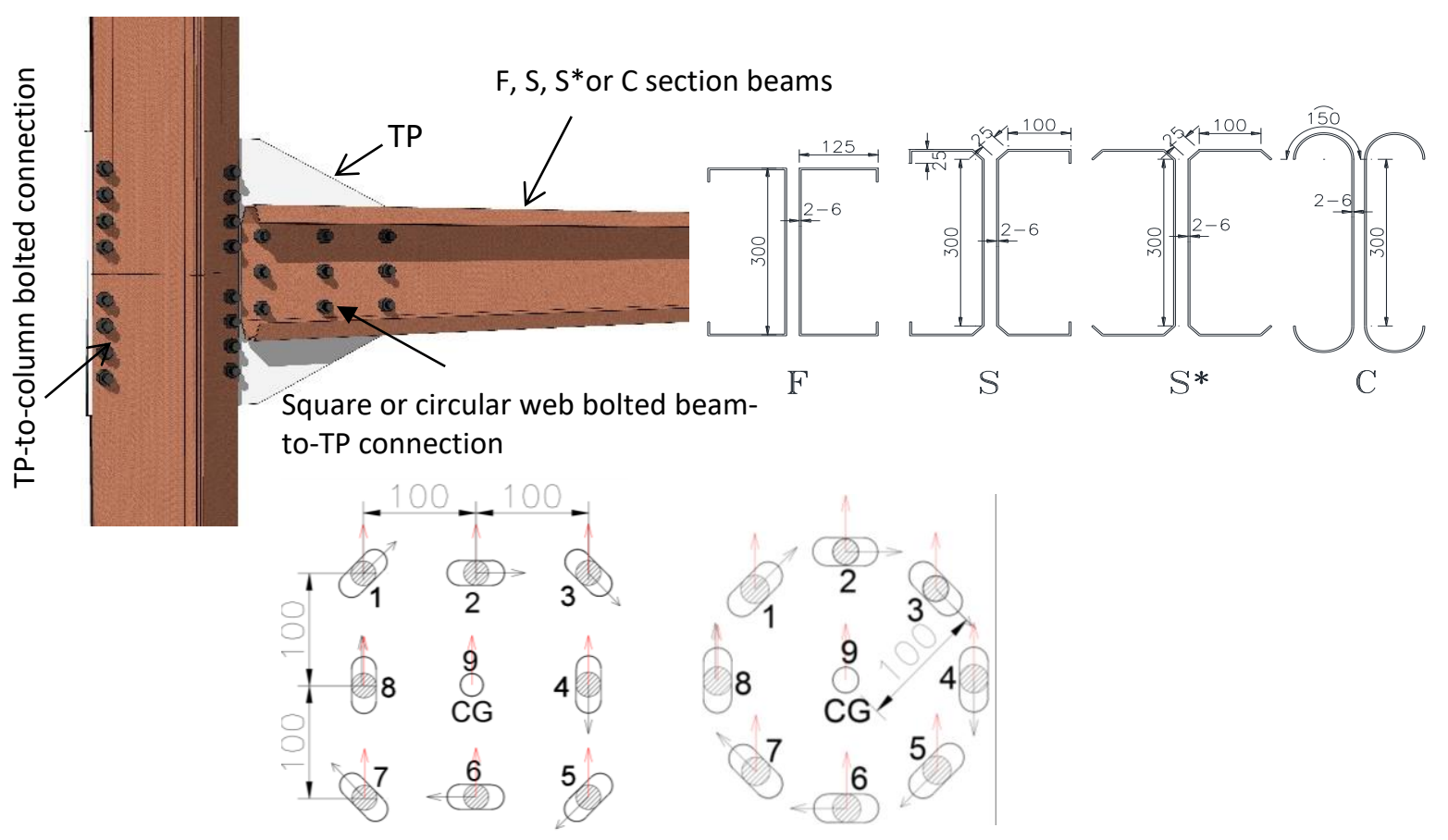

Sequential steps of shaping a curved flange beam using a press brake (after [4])
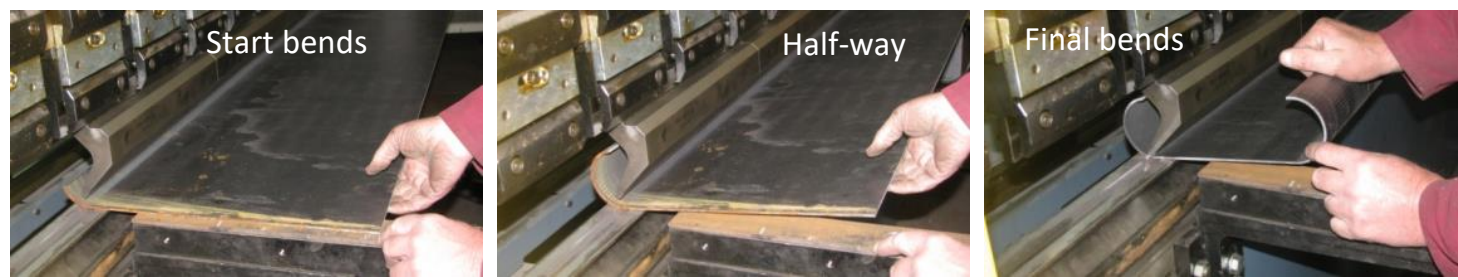

Figure 2. $C F S$ joints with $S B$ and $C B$ bolting and $F, S, S *$ and $C$ types of beam sections and manufacturing process of a $\mathrm{C}$ section using a press brake.

Friction-slip fuse mechanism of the bolts has been assumed in design as the main device to provide the joint ductility capacity. To postpone/eliminate the bolts` bearing action, straight slotted holes have been used with their half-length $(D / 2)$ determined as $r \times \vartheta_{\text {max }}+d / 2$ where $r$ is the radius of the bolt group, $\vartheta_{\max }$ is the maximum joint rotation calculated at the centre of the bolt group and $d$ is the bolt 
diameter (illustrated in Fig. 3). Assuming $d=20 \mathrm{~mm}, \vartheta_{\max }=0.1 \mathrm{rad}$ and $r=100 \mathrm{~mm}$, the total length of the slotted holes on TP would be $D=40 \mathrm{~mm}$, while the beam holes were drilled using the standard dimensions with $2 \mathrm{~mm}$ tolerance. This simplified calculation is to accommodate the required back and forth travelling distance for the bolts under cyclic loading. The elimination of bearing in the bolts is to avoid the ductility demand to be shifted into the beams which can end up with an unfavourable local buckling failure. Nine bolts (B1 to B9 as numbered in Fig. 2) have been positioned at the center-tocenter distance (in SB) or with radius (in CB) of $r=100 \mathrm{~mm}$ connecting the beam webs to the TP. The centre bolt (B9) is mainly to tie the beam-web and TP plates avoiding the web buckling failure within the connection region subjected to high stress concentration. Furthermore, the centre bolt (with a standard round hole), particularly in the beams where the shear force is insignificant, can provide a constraining effect between the perimeter bolts towards a more uniform bolt group rotation around the centre. This has been investigated through companion experiments which will be reported subsequently.

Fig. 3 also illustrates the design parameters of the proposed CFS MR joint. The primary design criterion of the joint is $M_{d}{ }^{\text {slip }}$, conn $<I / L M_{\text {max, beam }}$ ensuring the bending moment corresponding to the slippage of the bolt-group $\left(M_{d}^{\text {slip }}\right.$, conn), is less than the projected buckling moment in the beam to the bolt-group centre $\left(/ / L M_{\text {max, beam }}\right)$; where $/$ and $L$ are the distances from the free-end of the beam to the connection centre and to the section just after the connection region inside the beam where the through plate ends, respectively. This ensures achievement of the target design approach of dissipating energy through bolted connections as a fuse mechanism (represented by a rotational spring as illustrated in Fig. 3) prior to buckling/yielding in CFS beams. The bolts pre-tensioning forces can then be calculated using the available design codes [7] as reported in Appendix A. The actual bolt-group force distribution, however, will differ from the above idealised assumption, thus influencing the performance of the joint. This has been investigated in more details through FE modelling of various connection arrangements, as presented in the following sections. In calculation of the bolts pretension forces, a slip coefficient of 0.3 , corresponding to Class C friction surfaces [7], has been assumed. However, a reduced slip coefficient of 0.19 [12] could be adopted if the connection was exposed to aggressive outdoor environmental conditions with galvanised coating protection. To reach the same level of the bolts slip resistance as that of the design with the higher slip coefficient a greater bolts pretension force would be required in that case.

A design method to set a lower bound for the slip moment of the bolted connections can be developed by means of Direct Strength Method (DSM), prescribed in Appendix 1 of the North American Specification AISI S100 [17]. The elastic buckling moments, inputting into DSM, can be computed using the constrained finite strip software CUFSM [18] through which buckling "signature curves" of the 
beam sections in Fig. 2 have been calculated. The obtained signature curves include local and distortional buckling failure loads versus their half-wavelengths assuming the beams have been restrained against the global buckling modes. After calculation of the projected buckling moment of the beam, $I / L M_{\max }$ beam, as the maximum upper bound slip moment, a range of lower bound slip moments have been examined accounting for the uncertainties discussed in Section 4.

The bolts friction-slip mechanism, assumed in this work, is designed to slip at the Ultimate Limit State (ULS, in Eurocode 8 terminology [8]) in order to provide the required ductility. At the Damage Limitation State (DLS, in Eurocode 8 terminology [8]), however, the joint is designed to be rigid, satisfying the requirement of the joint elastic stiffness to be greater than $25 E I_{b} / /$ [7]. The latter refers to the elastic region of the moment-rotation curves at service loads before slip initiates which has been validated through the experiments on the CFS moment-resisting connections reported by the second author [3]. The through-plate was designed having $15 \mathrm{~mm}$ thickness to remain elastic at all Limit States, capable of resisting the projected $M_{\max }$, beam at the centre of the TP-to-column connection. The beam channel sections are connected back-to-back using filler plates at $500 \mathrm{~mm}$ distance required to prevent lateral-torsional buckling of each of the single channels along the length of the beam [17]. The potential bimoment effects due to eccentricity from the shear centre of the beam's single channel-section, as reported by Lim et al. [19], in local buckling failure was reduced by satisfying their recommendation on the minimum bolt-group length-to-height ratio of unity [19].

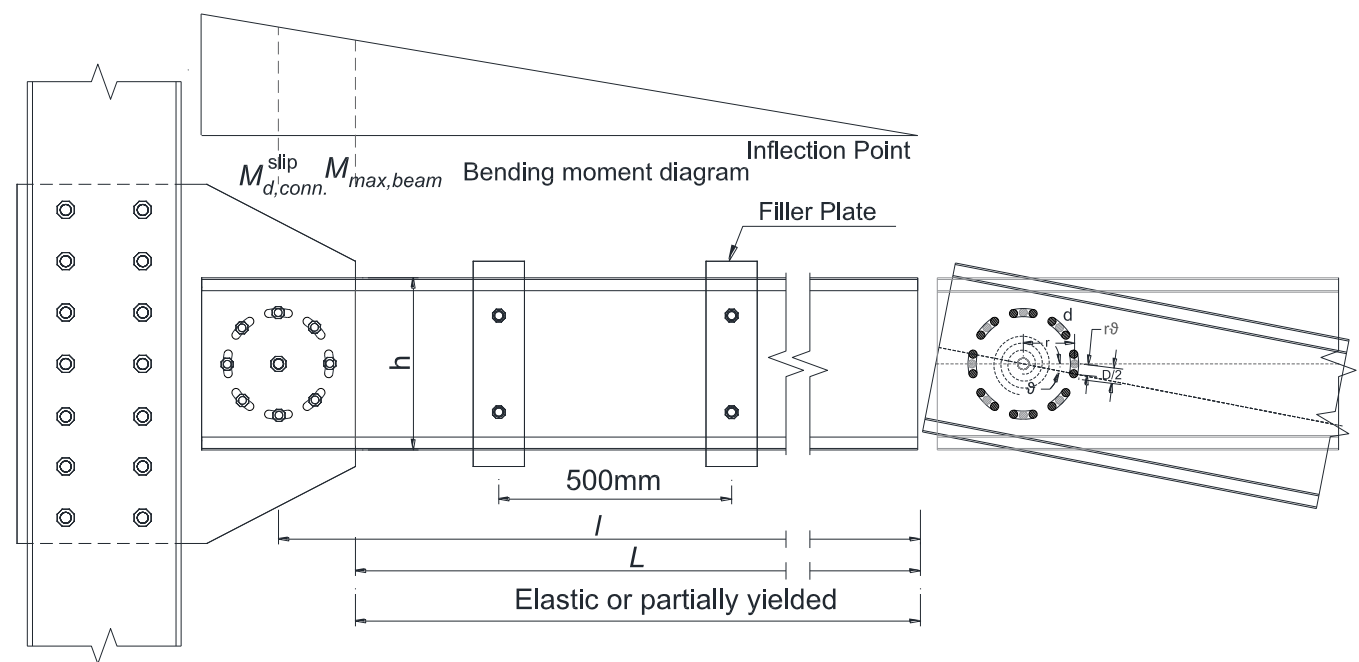

Figure 3. Design parameters of CFS joint.

\section{FE Modelling specifications and methodology}

Finite element (FE) modelling of the CFS connection was undertaken using the FE package ABAQUS 6.14 [16]. Fig. 4 shows a typical FE model of a $2.5 \mathrm{~m}$ length cantilever beam bolted to the TP in one end and loaded through the web lines at the free end of the beam. Nonlinear post-buckling analysis was performed using the Riks method available in ABAQUS which is suitable to predict instability and 
material and geometrical nonlinearity of a structure. This method takes the load magnitude as unknown and solves simultaneously for loads and displacements [16].

Columns have not been explicitly included in the initial FE models which mainly focuses on the monotonic performance of the beam-to-TP web bolted connection. The TP has therefore been fixed at the nodes where it is bolted to the column (see Fig. 4, models without columns). This method of modelling eliminates the contribution of the column member and its connection to the TP into the joint deformation. This contribution, however, can be insignificant if the columns were designed to remain elastic and the TP-to-column bolts were designed as slip-resistance type of connection with no bearing action. Therefore, the slip movements of the web bolted beam-to-TP connection and the beam bending remain the primary sources of the ductility capacity of the joint. The hysteretic moment-rotation curves of the models with incorporation of column members are presented in Section 6. The column sections are $10 \mathrm{~mm}$ thickness double back-to-back lipped channels with the web depth, flange width and lips of $300 \mathrm{~mm}, 150 \mathrm{~mm}$ and $25 \mathrm{~mm}$, respectively. The boundary condition of the two ends of the columns were assumed to be hinged (see Fig. 4, models with columns) representing inflection points assumed at the mid-length of a $3 \mathrm{~m}$ storey height moment-resisting frame. The TP-to-column slip-resistant bolts were modelled using rigid fastener connections.

To prevent out-of-plane instability, the top flanges of the beams were laterally restrained (in Xdirection) to represent the effect of the floor supported by the beams. The filler plates between the beam channel sections (see Fig. 3) have been modelled using tie constraints distanced at $500 \mathrm{~mm}$ along the length of the beam. The loading points (arrowed in Y-direction in Fig. 4) were at the free end of the beam through the web lines. To model the thin walls of the beam sections and the through plate, the second order S8R shell type was employed having 8 nodes, each with 6 translational and rotational degrees of freedom and reduced integration. A fine mesh size of $10 \mathrm{~mm} \times 10 \mathrm{~mm}$ was chosen through a separate mesh sensitivity analysis which is presented in Appendix B. Sharp corners are assumed in modelling of all types of the beams shown in Fig. 2 . The actual radius of the corners of the beams, which were tested afterwards, will be incorporated into updated FE modelling along with the measured imperfections and the material properties which will be reported subsequently. 


\section{Models without column (cantilever beam)}

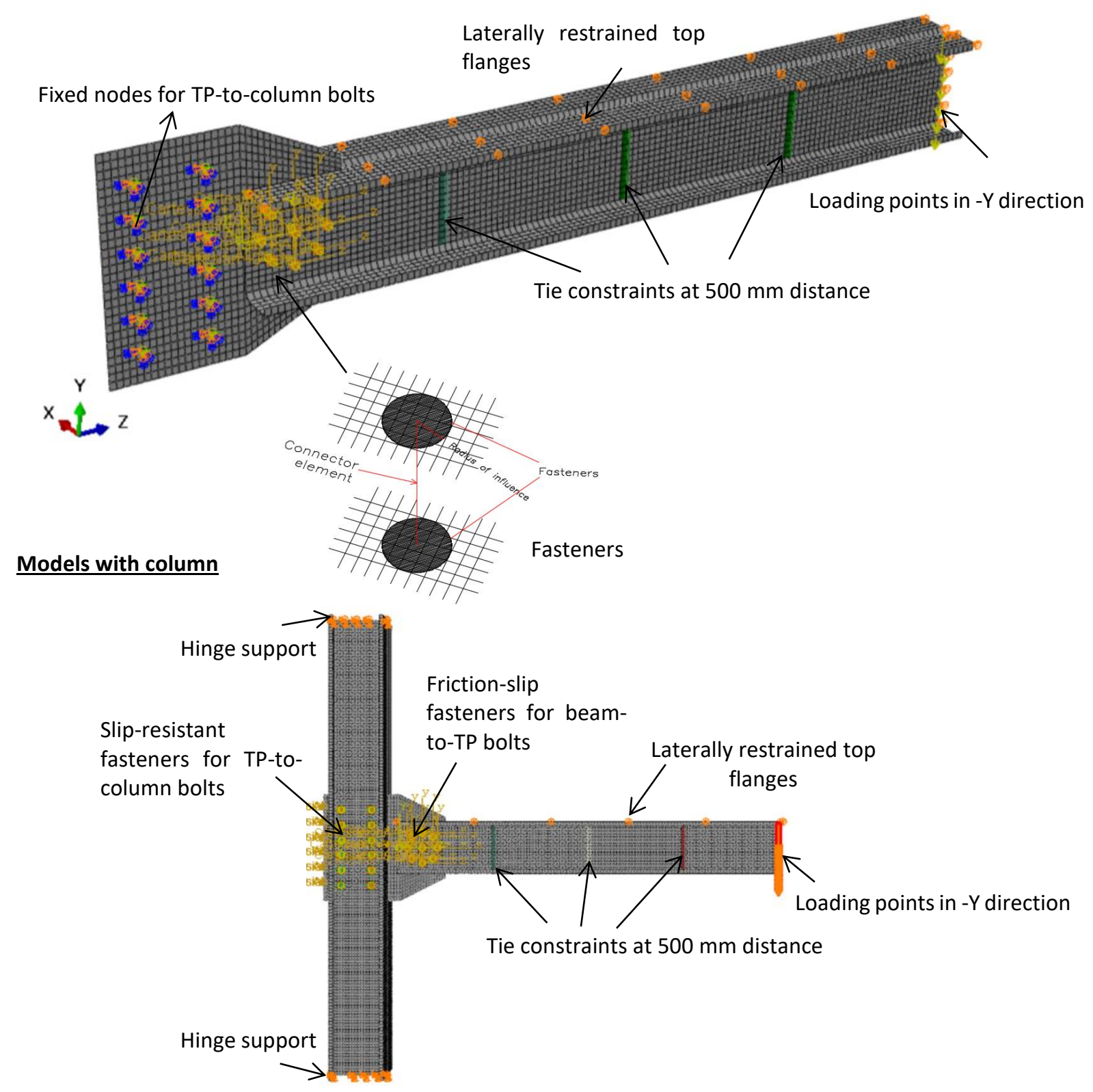

Figure 4. FE models of the CFS joint with and without columns: Boundary conditions, loading points and connector elements.

To model the beam-to-TP bolting, connector elements available in the ABAQUS library [16] have been adopted. Fig. 4 shows a Discrete FASTENER, which is a mesh independent surface connection method, employed for the connector elements. Fasteners bond the connector elements to the shell beam elements with the radius of influence equals to the bolt diameter. The connectors constitute a bilinear behaviour: (i) rigid up to the slip resistance limit of the bolts, $R_{\text {slip, }}$ and (ii) plastic when slip initiates. The S275 steel Grade has been used with yield strength $\left(f_{\mathrm{y}}\right)$ of $275 \mathrm{MPa}$, ultimate strength $\left(f_{\mathrm{u}}\right)$ of 485 $\mathrm{MPa}$, modulus of elasticity $\left(E_{0}\right)$ of $210 \mathrm{GPa}$ and Poission`s ratio of 0.33 . A bi-linear stress-strain curve has been used for the adopted steel with the strain hardening ratio of $E_{1} / E_{0}=0.01$. 
As is common practice, residual stresses were not included in the FE models, implicitly balancing out the beneficial cold-work effects of forming which are dependent to one another [20]. This assumption has been widely adopted in numerical modelling of cold-formed steel in which the FE models were successfully validated against the test results $[6,21]$.

\section{FE results and discussion on the bolting friction-slip mechanism effects}

Fig. 5 presents the normalised moment-rotation $\left(M / M_{p}-\vartheta\right)$ curves obtained from the FE analysis of the CFS MR joints (see Fig. 2) for $300 \mathrm{~mm}$ deep beams, in which $M_{\mathrm{p}}$ is the plastic bending moment of the corresponding F-section (for consistency purposes). Both $M$ and $\vartheta$ have been calculated at the centre of the beam-to-TP bolt-group. These include $M / M_{p}-\vartheta$ curves for SB (square bolting) and CB (circular bolting) connections (drawn by solid and dashed lines, respectively), with F, S, S* and C cross-sections (see Fig. 2), each with 2, 4 and $6 \mathrm{~mm}$ range of thicknesses. Furthermore, the projected buckling moments of the beams to the connection centre ( $/ / L M_{\max }$, beam), assumed as the maximum upper bound slip moments, have been calculated based on DSM [17], as discussed previously in Section 2 (shown by the horizontal dotted lines in Fig. 5). A range of lower bound slip moments, corresponding to the bending moments of $0.3 M_{p}, 0.5 M_{p}$ and $0.7 M_{p}$ (shown by different line thicknesses) at the boltgroup centre, have been assumed at which the slip force of the bolt-group has been triggered. The results of the SB connections without slip are also included for comparison purposes (shown by the thickest line). The $C B$ connections without slip resulted in $M / M_{p}-\vartheta$ curves which were similar to those of the SB connections and, therefore, has not been added in the graphs. The horizontal dotted lines (the DSM design in Fig. 5) are reasonably close to the peak moments of the curves without slip. These upper bound DSM lines (particularly for $2 \mathrm{~mm}$ thickness beams) seem to be more accurate for $F$ sections which fall into pre-qualified sections according to Appendix 1 of the North American Specification AISI S100 [17]. The reason being a pure bending moment stress distribution is assumed in DSM while this ideal stress distribution may not be reached in the FE analysis, particularly for lower thickness beams with $2 \mathrm{~mm}$ thickness, for which the buckling bending moments (for all the section shapes) occurred prior to the yielding bending moment. For higher thickness beams ( 4 and $6 \mathrm{~mm})$, however, a very good agreement between the DSM and FE results have been achieved even for the unqualified sections ( $S, S^{*}$ and $C$ ). The exception being the $6 \mathrm{~mm} \mathrm{C}$ section for which the FE peak moment exceeds $M_{p}$ while the DSM is limited to the section yielding moment.

The $M / M_{p}-\vartheta$ curves for all the SB and CB joints without slip and with slip level of $0.7 M_{p}$ (with the exception of $6 \mathrm{~mm}$ thickness beams) show a sharp strength degradation after the peak $M$; whilst all the joints with the lower slip levels of $0.3 M_{p}$ and $0.5 M_{p}$ sustain a larger deformation without strength degradation (larger than the 0.04rad required for Special Moment Frames [9]). Therefore, activation of connection slip is highly beneficial to achieve higher ductility capacity particularly for joints with 
lower beam thicknesses which would otherwise be more prone to local buckling due to their thin walled nature. Within the range of the investigated CFS joints those with $0.5 M_{p}$ slip level provide higher strength than the joints with $0.3 M_{p}$ slip level, both with a high ductility capacity. Therefore, activation of connection slip at $0.5 \mathrm{M}_{\mathrm{p}}$ slip is more efficient to achieve both high strength and ductility capacity.

On comparing the curves for the $\mathrm{SB}$ and $\mathrm{CB}$ connections, in all cases, departure from the initial linear response can be seen on the figure to occur at the moment level specified for bolt slip to begin. However, a key difference between most of the SB and CB cases is that there is a greater increment in moment capacity after the initial bolt slip in the SB cases than in the CB cases, because of the greater non-uniformity in the bolt loads in the former. This initial slip occurs as the bolts at the furthest distances from the bolt-group centre of rotation reach the slip load limit, after which the bolt forces are redistributed into the bolts initially carrying less load. This continues until all the bolts reach the slip limit and then the bolt-group undergoes slip as a whole. This redistribution is, conservatively, not included in the conventional design approach, but in this context the additional moment that results from this redistribution could end up with unexpected beam yielding and premature local buckling. The $\mathrm{CB}$ connections, on the other hand, are characterised by a more uniform bolt force distribution, and hence less of this additional and undesirable moment, leading to a more reliable design.

By comparing the $M / M_{p}-\vartheta$ results (Fig. 5), it will be seen that the curves obtained for the different cross-sections $\left(F, S, S^{*}\right.$ and $\left.C\right)$ at the various slip levels $\left(0.3 M_{p}, 0.5 M_{p}\right.$ and $\left.0.7 M_{p}\right)$ are following similar trends with relatively close strength and ductility capacity. This indicates that the connection frictionslip behaviour, when it determines the design capacity, is independent of the choice of beam sections.

Table 1 presents the stress contours obtained from the FE analysis for the yielded areas (shown by darker shades) at the peak moments for the representative $300 \mathrm{~mm}$ deep S-beam with both SB and $\mathrm{CB}$ connections at the various slip levels. As can be seen, by increasing the slip resistance level from $0.3 M_{p}$ to $0.7 M_{p}$ larger yielded areas have been developed in the beams outside the connection region. This indicates higher ductility demand in the CFS beams which can end up with unfavourable local buckling failure. Larger yielded areas within the connection region of the joints with the lower level of slip indicate a more significant contribution of this area into the joint ductility demand through the bolts friction-slip mechanism.

In general, given the uncertainties related to the bolt force distribution and DSM buckling moment prediction for unqualified sections (particularly for lower thickness beams), a slip moment of less than one half of the upper bound DSM moment for the equivalent $F$ section beams would be recommended. For the range of sections examined herein, for instance, the recommended slip moments would be around $0.3 M_{p}, 0.4 M_{p}$ and $0.45 M_{p}$ for 2,4 and $6 \mathrm{~mm}$ thickness beams, respectively. 

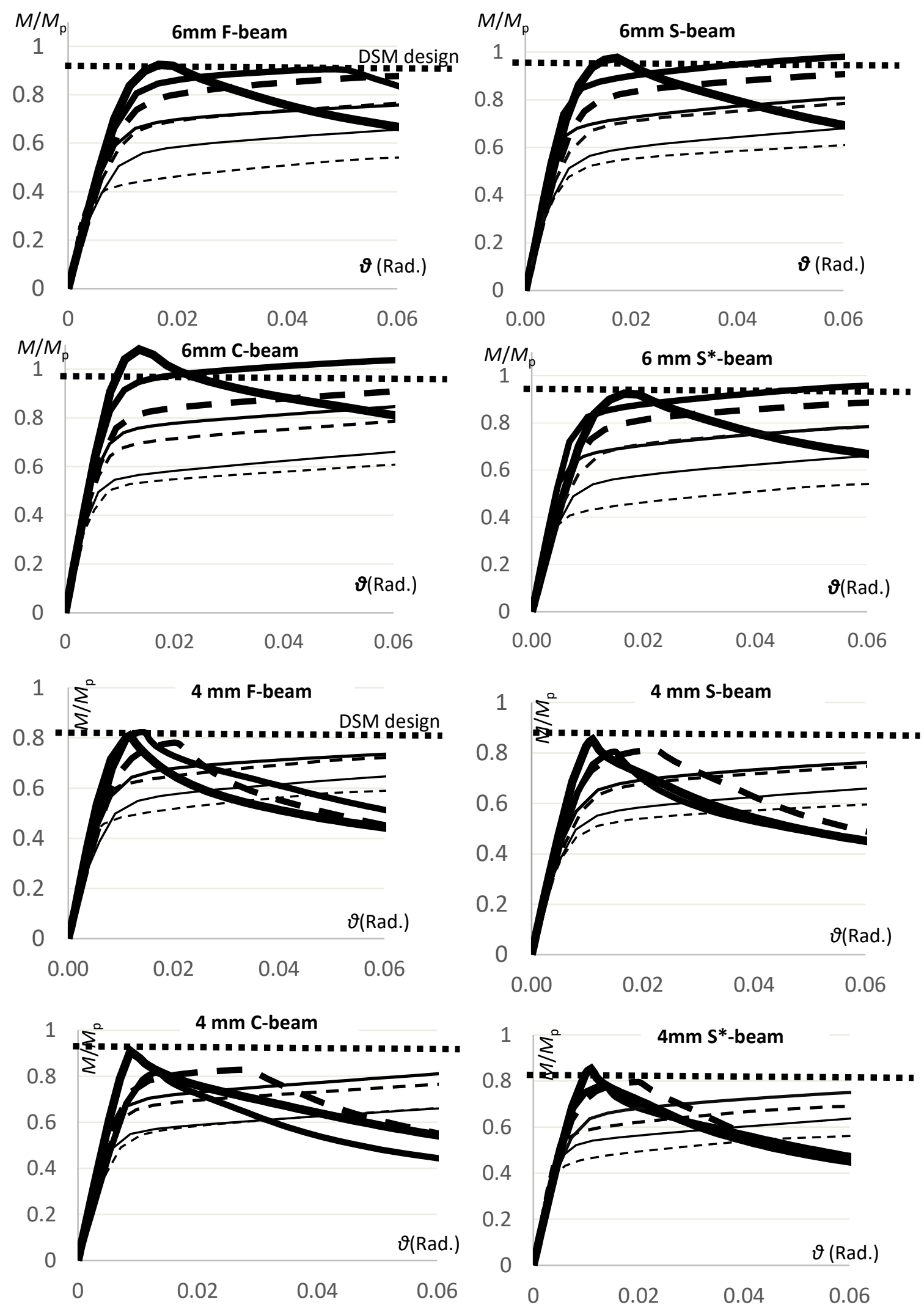

SB: solid line. $\mathrm{CB}$ : dashed line. Without slip $=0.7 \mathrm{M}_{\mathrm{p}}$ slip $-0.5 \mathrm{M}_{\mathrm{p}}$ slip $-0.3 \mathrm{M}_{\mathrm{p}}$ slip Figure 5. $M-\vartheta$ curves and DSM design for $S B$ and $C B$ connections with $300 \mathrm{~mm}$ deep $F, S, S^{*}$ and $C$ beams with 2-6 $\mathrm{mm}$ thicknesses, without slip and with slip loads of $0.3 \mathrm{Mp}_{\mathrm{p}}, 0.5 \mathrm{Mp}, 0.7 \mathrm{Mp}_{\mathrm{p}}$. 

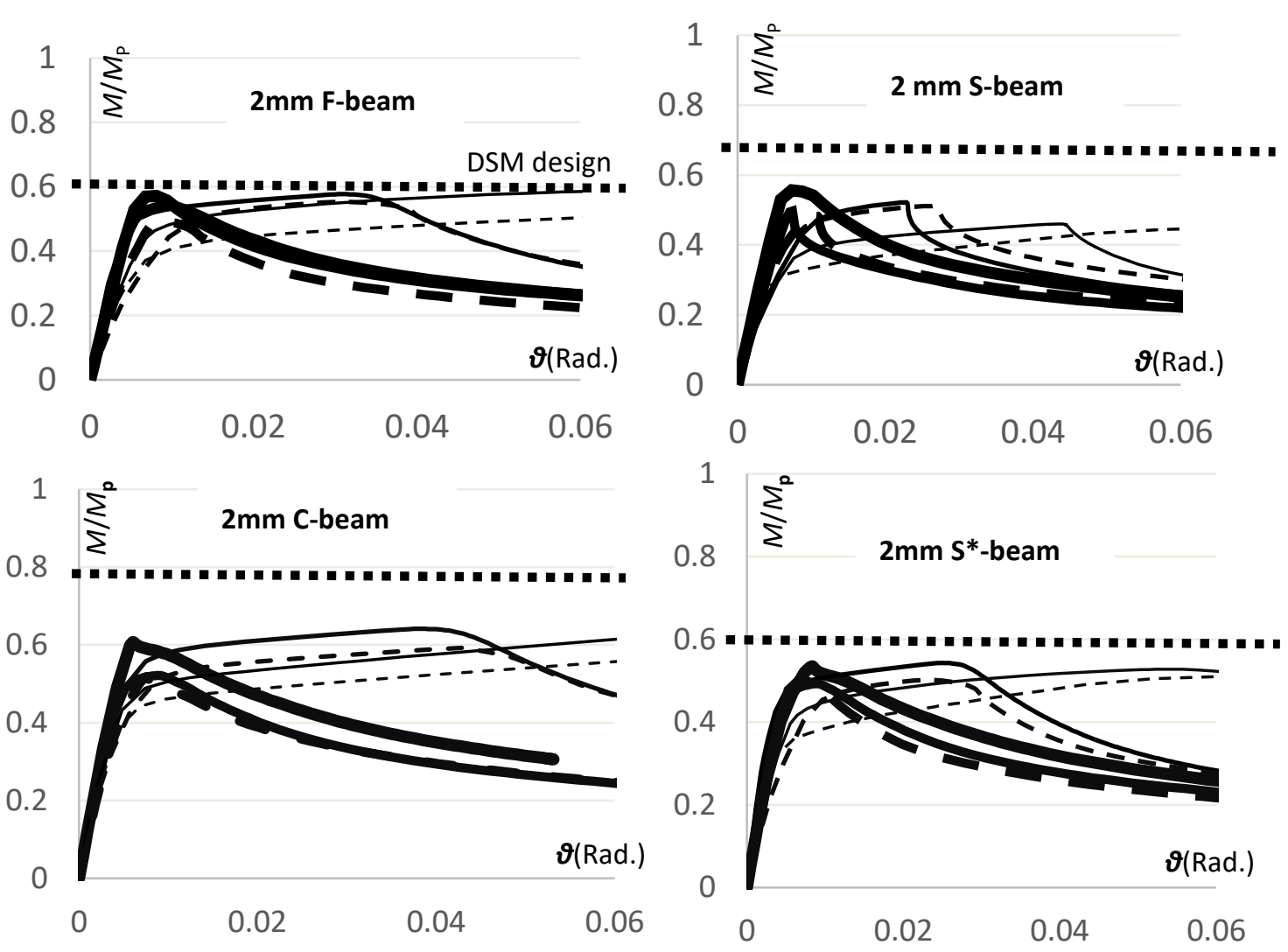

SB: solid line. CB: dashed line. Without slip

$0.7 M_{p}$ slip $=0.5 M_{p}$ slip $\quad 0.3 M_{p}$ slip

Figure 5 (continued). $M-\vartheta$ curves and DSM design for SB and CB connections with $300 \mathrm{~mm}$ deep $F, S, \mathrm{~S}^{*}$ and $C$ beams with 2-6 mm thicknesses, without slip and with slip loads of $0.3 M_{\mathrm{p}}, 0.5 \mathrm{Mp}_{\mathrm{p}}, 0.7 \mathrm{Mp}$. 
Table 1. Yielding stress distribution at the peak $M$ for SB and CB connections with $300 \mathrm{~mm}$ deep S-beam with 2 and $6 \mathrm{~mm}$ thickness

Slip at:

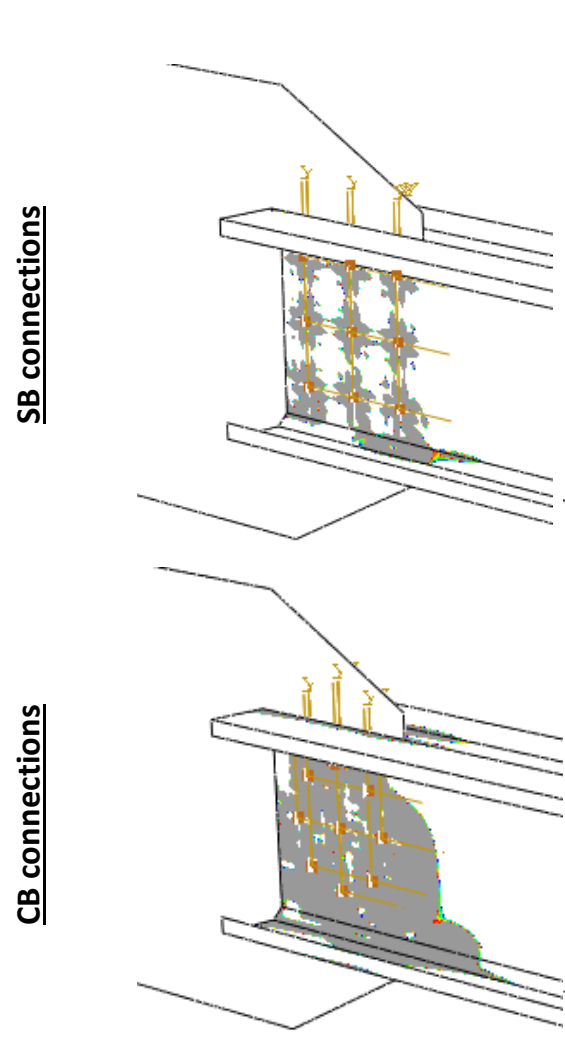

ติ

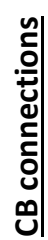

$0.3 M_{p}$
$0.5 M_{p}$

$2 \mathrm{~mm}$ beams

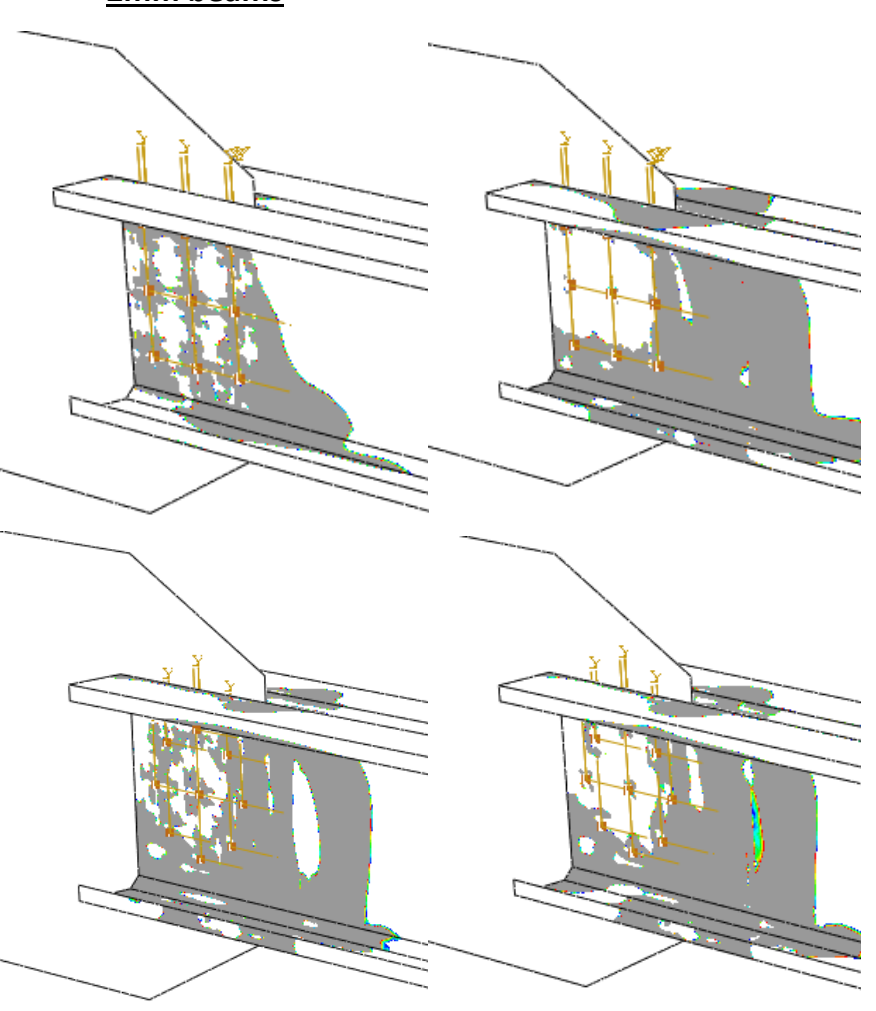

$6 \mathrm{~mm}$ beams
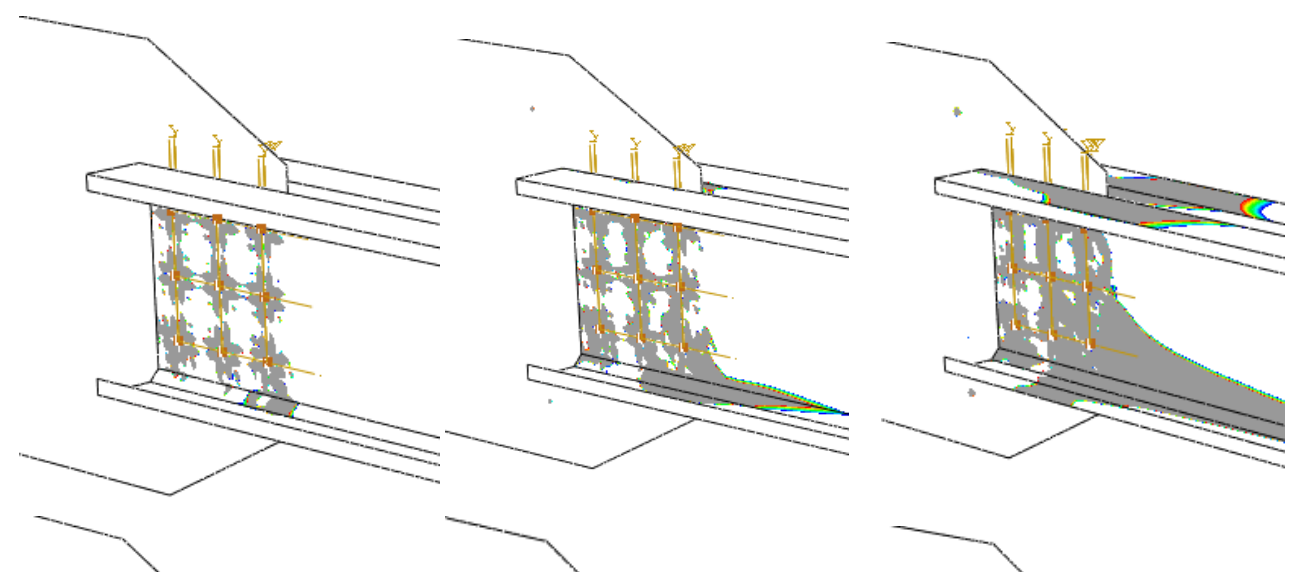
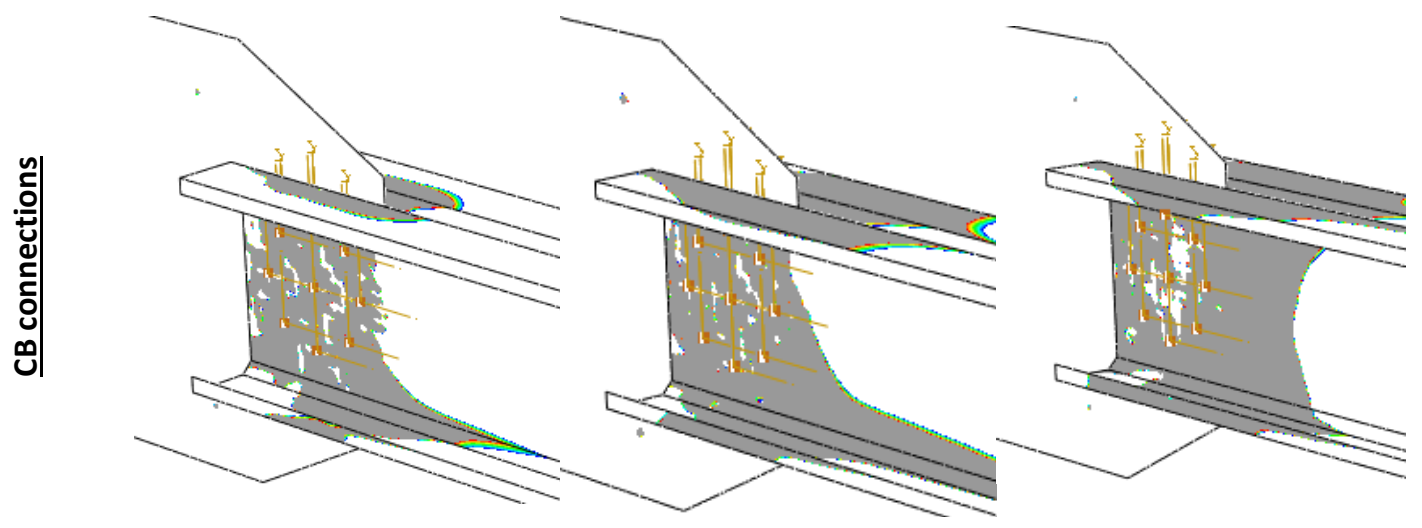
The results obtained for the joints with $200 \mathrm{~mm}$ deep beams were similar to those of the joints with $300 \mathrm{~mm}$ deep beams as presented above with the exception of the joints with $2 \mathrm{~mm}$ beam thickness. As can be seen in Fig. 6 all the $M / M_{\mathrm{p}}-\vartheta$ curves for the $200 \mathrm{~mm} \mathrm{SB}$ and CB connections with $2 \mathrm{~mm}$ beams are noticeably close to each other and activation of the connection slip at $0.7 M_{p}$ and $0.5 M_{p}$ has not meaningfully improved the ductility performance. The reason for this can be explained through inspection of Table 2 showing the yielded areas of the joints for the representative S-beam with slip levels at $0.7 M_{p}$ and $0.5 M_{p}$. As can be identified, all the joints have been affected by a premature flange local buckling and, therefore, underwent strength degradation even before activation of the connection slip. Activation of slip at $0.3 \mathrm{M}_{\mathrm{p}}$, however, postponed occurrence of buckling and led to a higher ductility capacity of the connection. This also reasonably complies with the aforementioned recommendation for the connection slip level less than one half of the DSM design for F section.
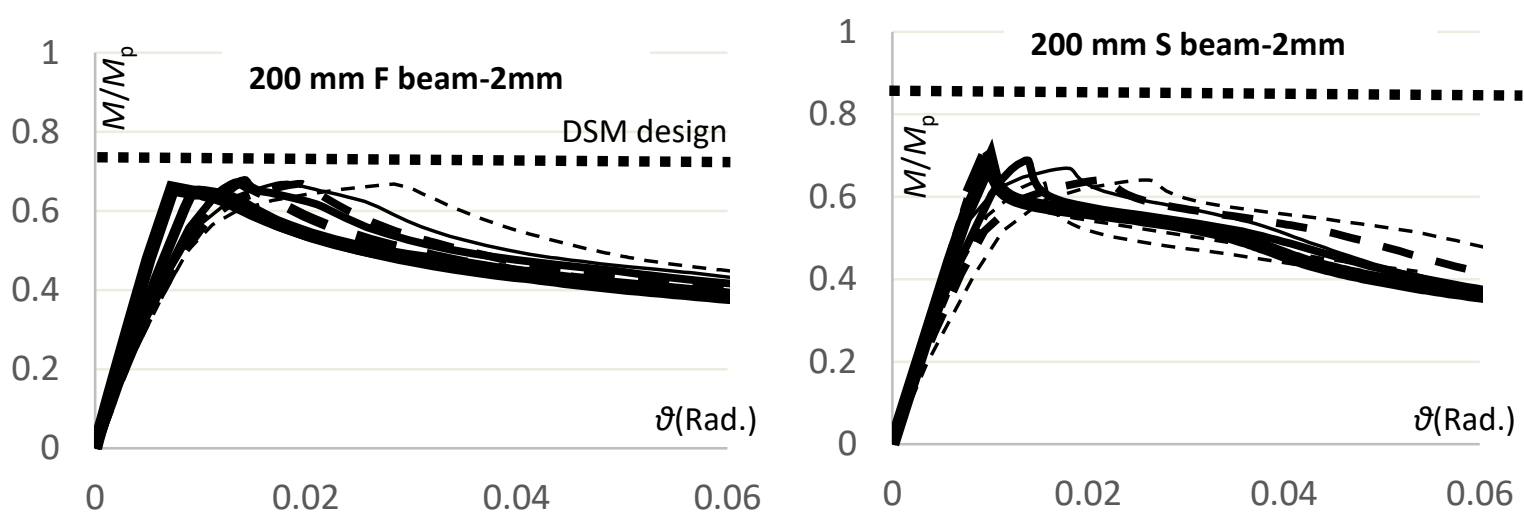

SB: solid line. CB: dashed line. Without slip $0.7 M_{p}$ slip

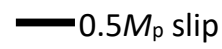
$0.3 M_{\mathrm{p}}$ slip

Figure 6. $M-\vartheta$ curves and DSM design for SB and CB connections with $200 \mathrm{~mm}$ deep $\mathrm{F}$ and $\mathrm{S}$ beams with $2 \mathrm{~mm}$ thicknesses, without slip and with slip loads of $0.3 M_{\mathrm{p}}, 0.5 \mathrm{Mp}, 0.7 \mathrm{Mp}$. 
Table 2. Yielding distribution at peak $M$ for connections with $200 \mathrm{~mm}$ deep $\mathrm{S}$ beam with $2 \mathrm{~mm}$ thickness

at:
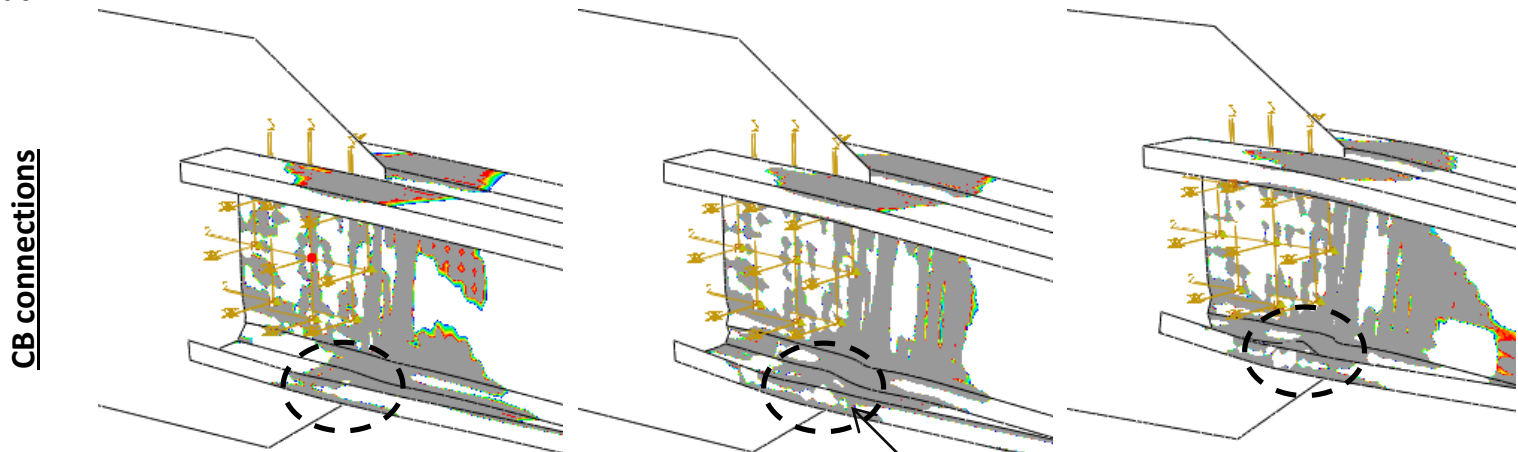

Localbuckling
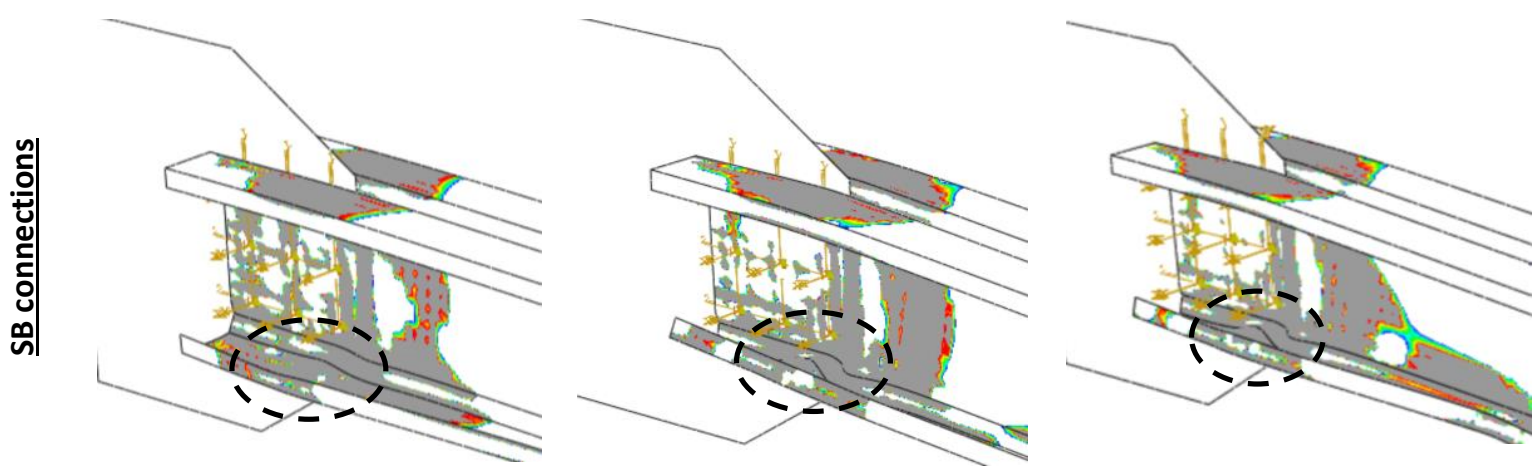

\section{Bolting arrangement effects and instantaneous centre of rotation(ICR)}

A more detailed comparison between the bolt-group force distribution of the $\mathrm{CB}$ and $\mathrm{SB}$ connections is presented in Fig. 7 showing all the bolt forces (B1 to B9) of the representative joints with 300 mm deep, $4 \mathrm{~mm}$ thickness S-section beams. The results were obtained for all the joints without slip and with the different slip levels of $0.3 M_{p}, 0.5 M_{p}$ and $0.7 M_{p}$. As can be seen, the bolt forces of the $C B$ connections are noticeably less deviated from each other than those of the SB connections. This underpins the concluding remark of the more uniform bolt-group force distribution of $C B$ connections as discussed in Section 4. Referring to Fig. 7 bolt B9 (shown by thin dashed lines), located at the centre of the bolt-group, attracts a relatively small force, as expected. Bolts B3 and B5 (shown by solid lines), with the furthest distances from the centre of rotation, resist the largest share of the forces in connections both with and without slip - at least in the early stages of loading before bolt force redistribution due to initiation of slip or beam local buckling. The bolt forces of the connections with slip are limited to the design slip load level of the bolts (shown by the plateau in the B3 and B5 lines) and hence all the bolt forces, apart from the centre bolt B9, tend to approach that level, with B3 and $B 5$ reaching it first. As expected, the $\mathrm{CB}$ connections show more uniform bolt forces with bolt forces faster converging on the slip load value. However, this pattern of behaviour breaks down if the moment in the beam section has been high enough to cause local buckling of the beam section (connections with $0.7 M_{p}$ slip), with its consequent loss of moment capacity in the corresponding $M / M_{p}-\vartheta$ curves of Fig. 5 , in which case the bolt force distribution remains very unequal. 

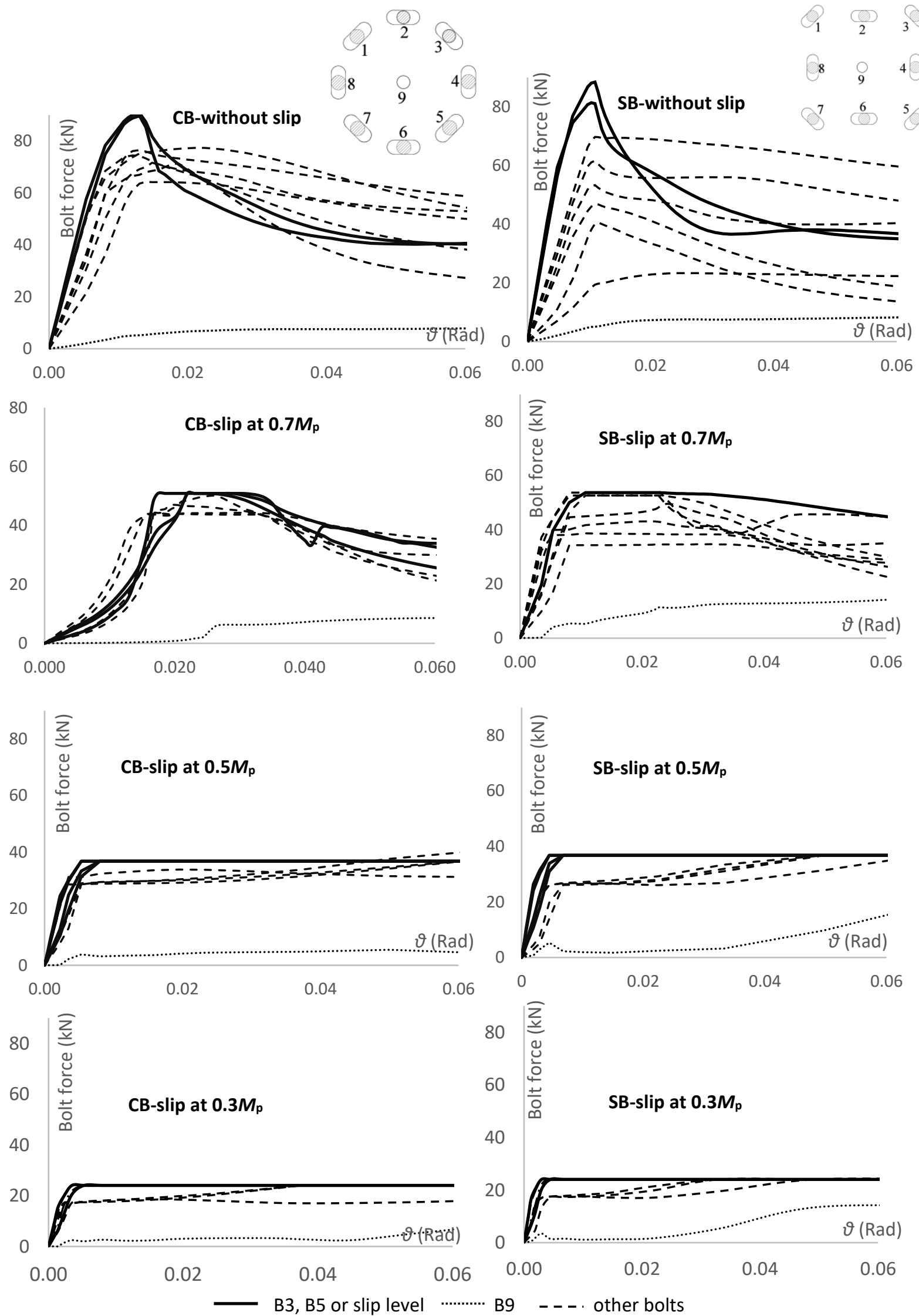

Figure 7. Bolt forces $B 1$ to $B 9$ of the $S B$ and $C B$ connections of the joints with $300 \mathrm{~mm}$ high, 4 mm thickness $\mathrm{S}$ section beam without slip and with slip levels of $0.7 \mathrm{Mp}, 0.5 \mathrm{Mp}$ and $0.3 \mathrm{Mp}$. 
For the representative $300 \mathrm{~mm}$ deep, $4 \mathrm{~mm}$ thickness S-section CB and SB joints, Fig. 8 shows the variation of the instantaneous centre of rotation (ICR) from the bolt group centroid along the horizontal direction normalised by the length of the bolt-group (i.e. $200 \mathrm{~mm}$ in all cases). A standard design method has been adopted for the ICR calculation, as summarised in Appendix $C$ and shown by dotted lines at around $0.5 \%$ in Fig.8. For the CB and SB connections with the various slip load levels, the normalised ICRs reach a maximum of $2.6 \%$ and $3 \%$, respectively and remain reasonably constant after the slip initiation. Such relatively small ICR deviations from the bolt group centroid do not have meaningful impact on design of the bolts in practice. For the $C B$ and SB connections without slip, however, a sharp increase of ICRs occurred at around 0.02-0.03 rad rotation reaching $11 \%$ and $15 \%$ at 0.06 rad rotation, respectively. This can be attributed to the strength degradation due to the beam local buckling in the connections without slip (reflected in Fig. 5), which causes significant deviations in the bolt forces, as seen in Fig. 7. Prior to this sharp increase, the ICR is very close to the values for the connections with slip.

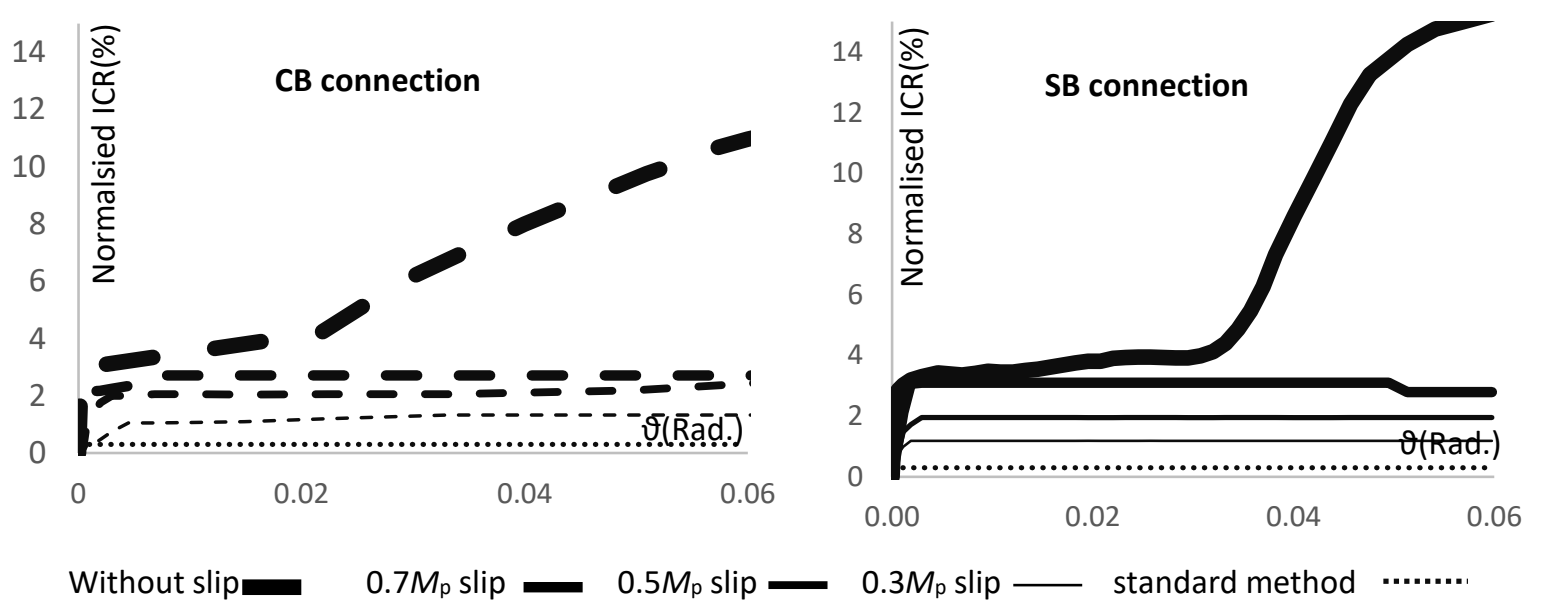

Figure 8. Variation of ICR for SB and CB connections of the joints with $300 \mathrm{~mm}$ deep, $4 \mathrm{~mm}$ thickness S-section beam without slip and with slip levels of $0.3 M_{p}, 0.5 M_{p}$ and $0.7 M_{p}$.

\section{Cyclic loading and hysteretic energy dissipation capacity of the SB and CB connections}

To determine the seismic energy dissipation capacity of the developed CFS MR connections, a cyclic loading protocol has been adopted from the AISC seismic provisions [9] as presented in Fig. 9, which is specified through the following cycles: (1) six cycles at $\vartheta=0.00375 \mathrm{rad}$; (2) six cycles at $\vartheta=0.005 \mathrm{rad}$; (3) six cycles at $\vartheta=0.0075 \mathrm{rad}$; (4) four cycles at $\vartheta=0.01 \mathrm{rad}$; (5) two cycles at $\vartheta=0.015 \mathrm{rad}$; (6) two cycles at $\vartheta=0.02 \mathrm{rad} ;(7)$ two cycles at $\vartheta=0.03 \mathrm{rad}$; (8) two cycles at $\vartheta=0.04 \mathrm{rad}$; and (9) continue loading at increments of $\vartheta$ equal to $0.01 \mathrm{rad}$, with two cycles of loading at each step. This protocol is used for qualifying moment-resisting joints as special and intermediate moment frames. 


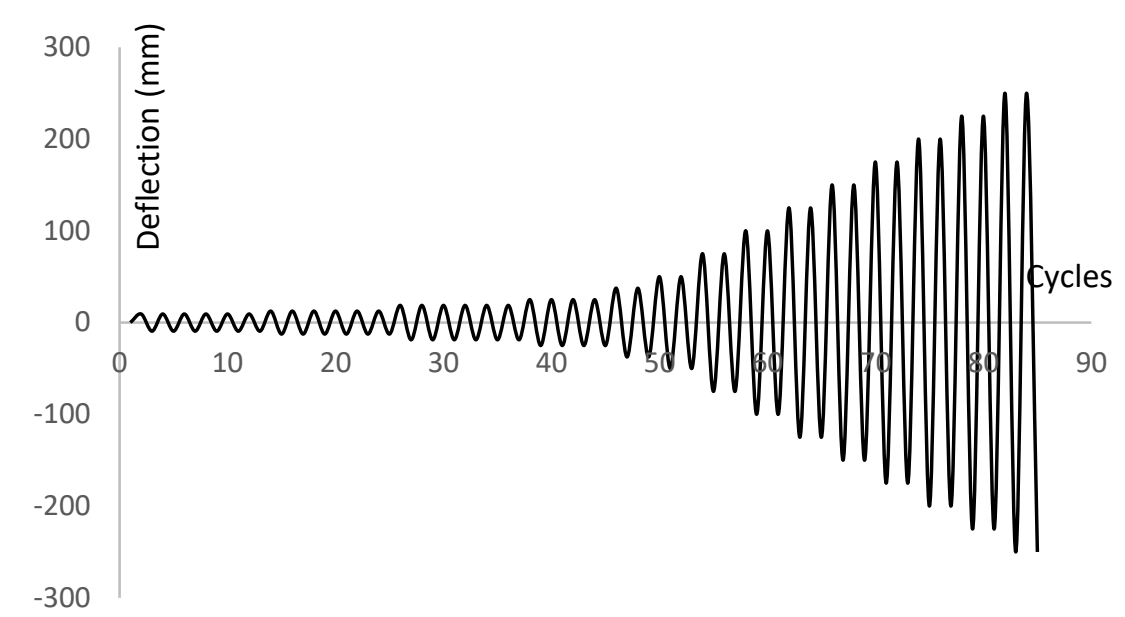

Figure 9. Loading protocol in accordance with the AISC seismic provisions [9]

Fig. 10 shows the hysteretic responses of the representative joints with SB and CB connections of 300 $\mathrm{mm}$ deep, $4 \mathrm{~mm}$ thickness S-section beam without slip and with slip at $0.3 M_{\mathrm{p}}$ and $0.5 M_{\mathrm{p}}$. It can be identified that the hysteretic curve without slip reaches a peak moment of $0.88 M_{p}$ and $-1.06 M_{p}$ in the positive and negative sides, respectively, after which a strength degradation initiated due to the beam local buckling. This caused a slackening effect in the hysteretic curves which significantly reduces the energy dissipation capacity of such connections. On the other hand, the hysteretic curves corresponding to the connections with slip at various levels are more stable with no strength degradation and slackening effect. Therefore, around 75\% higher cumulative energy dissipation (as presented in Fig. 11) were achieved at 0.06rad, for the CB and SB connections with slip at $0.5 \mathrm{M}_{\mathrm{p}}$, compared with that of the connection without slip. The cumulative energy dissipation curves (in Fig. 11) were calculated at $0.01 \mathrm{rad}$ intervals as the areas surrounded by the cyclic loops of the hysteretic curves. Inspecting these curves, even the connections with slip level as low as $0.3 M_{p}$ dissipate up to $60 \%$ higher energy than the connection without slip. This highlights the unfavourable influence of local buckling and slackening effect on the hysteretic curves which can be avoided by appropriate design of a friction-slip mechanism in the bolt group.

Figs. 10 and 11 also include the hysteretic and the energy dissipation curves of the models with incorporation of the column members and the TP-to-column connection (shown by grey dotted lines) with the assumptions explained previously in Section 3 . The results were close to those of the models without columns. The only identified difference, as expected, is the connection stiffness being slightly higher in the initial models without columns (i.e. cantilever beams), which has insignificant influence on the overall connection behaviour, strength and the cumulative energy dissipation (as shown in Figs. 10 and 11).

To achieve the targeted friction-slip performance, as discussed before, bolting arrangement is a key design element for which an indication of the length of the slotted holes was obtained through the FE cyclic simulations. Based on the obtained bolts cyclic movements (presented in Fig. 12), a conservative 
$8 \mathrm{~mm}$ clearance, at each end of the slot, is predicted for the bolt holes, corresponding to the movement in the most critical bolt (i.e. bolt B3 as seen in Fig. 7). This agrees well with the simplified calculation given by $r \times \vartheta_{\max }$ which results in $10 \mathrm{~mm}$ clearance with $r=100 \mathrm{~mm}$ and a conservative $\vartheta_{\max }$ $=0.1 \mathrm{rad}$. Based on this calculation, a total length of $D=40 \mathrm{~mm}$ bolt slot is required for a $d=20 \mathrm{~mm}$ diameter bolt following the design concept previously explained in Section 2. Given the very small difference in the positions of the bolt group centroid and the instantaneous centre of rotation (Fig. 8), the slots can be arranged as tangential to arcs about the centroid (as shown on Fig. 3). This ensures sufficient travelling distance for the slipping bolts within the slotted holes. Therefore, the hardening effect of the bolts bearing action which can potentially ended up with the beam local buckling is postponed.

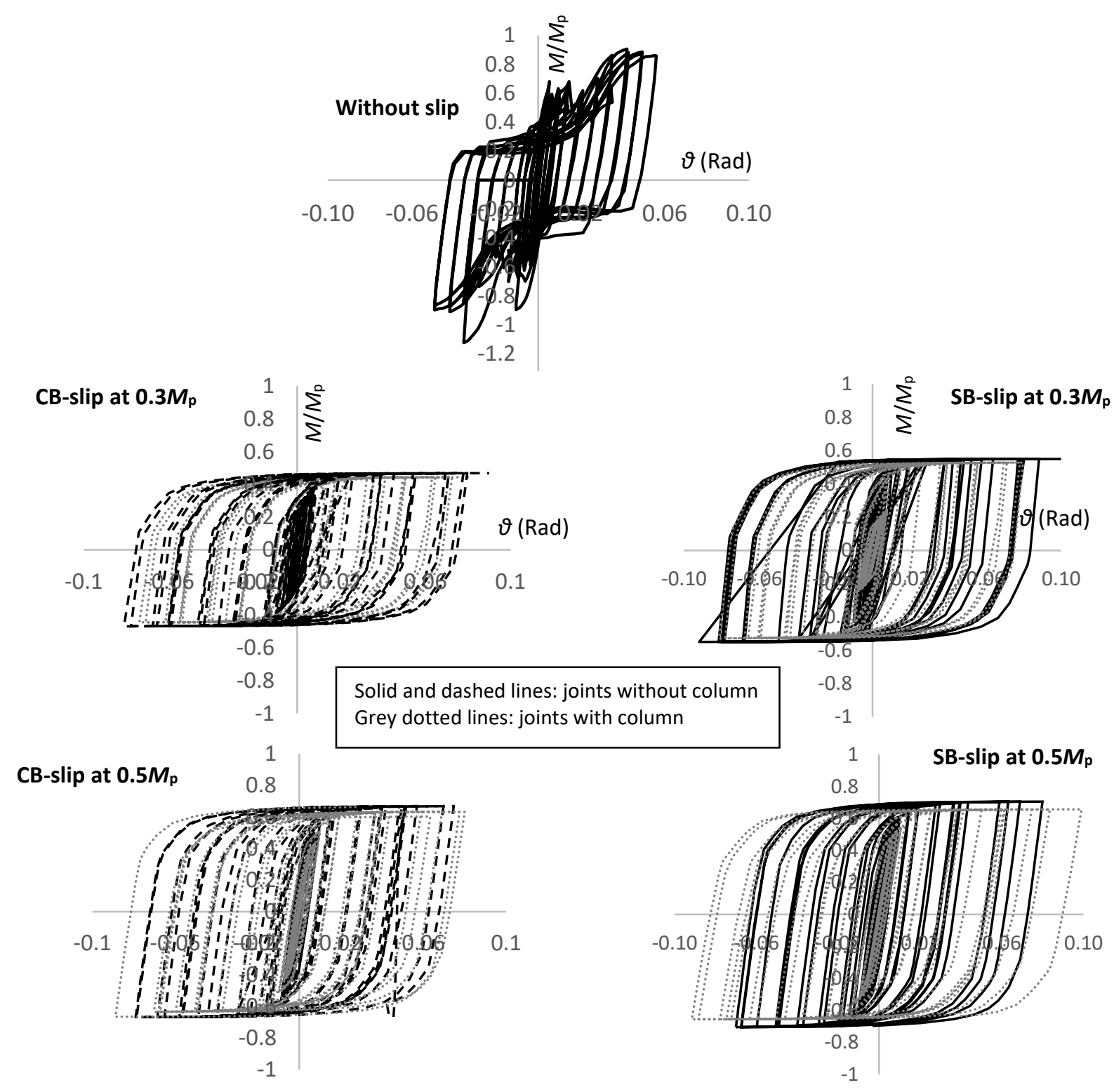

Figure 10. Hysteretic responses of SB and CB connections of the joints with $300 \mathrm{~mm}$ deep, $4 \mathrm{~mm}$ thickness Ssection beam without slip and with slip levels at $0.3 \mathrm{Mp}$ and $0.5 \mathrm{Mp}_{\mathrm{p}}$ with and without columns 


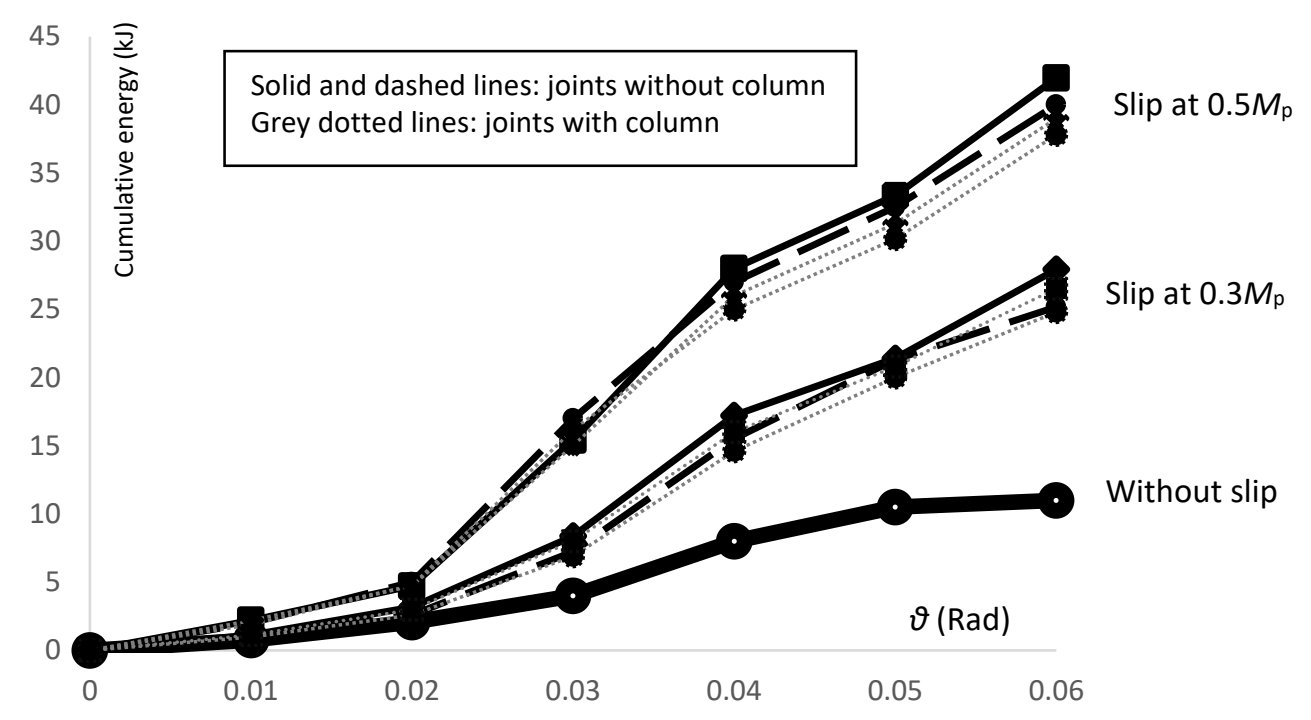

Figure 11. Cumulative energy dissipation curves of SB (solid line) and CB (dashed line) connections of the joints with $300 \mathrm{~mm}$ high, $4 \mathrm{~mm}$ thickness S-section beam without slip and with slip levels at $0.3 M_{\mathrm{p}}$ and $0.5 \mathrm{Mp}_{\mathrm{p}}$ with and without (grey dotted lines) columns

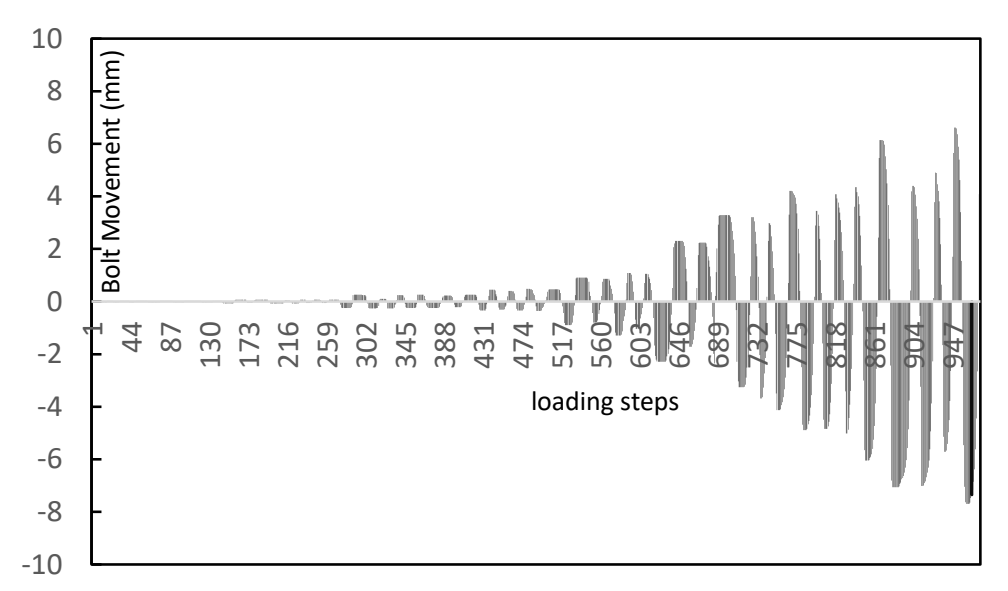

Figure 12. Bolt movements for bolt B3 of $300 \mathrm{~mm}$ high, $4 \mathrm{~mm}$ thickness S-beam, SB-slip at $0.5 \mathrm{Mp}$.

\section{FE validation}

The FE results presented herein have been fed into a series of full-scale tests under cyclic loading (conducted at the Building and Housing Research Centre (BHRC) of Iran) to validate the predicted performance of the developed CFS MR connections with incorporated friction-slip mechanism, and slotted holes as per the previous section. Fig. 13 shows an overall view of a test specimen with CB connections positioned in vertical direction connected to a strong floor in one end and loaded at the tip of the beam through horizontal actuators fixed on the test rig. For validation purposes the test and the FE hysteretic curves, using solid and dashed lines, respectively, for the CB-connection example having $4 \mathrm{~mm}$ thickness $\mathrm{S}$-section beam with slip initiation at $0.5 \mathrm{Mp}_{\mathrm{p}}$ are presented in Fig. 14. On comparing the curves, good agreement between the FE and the test results can be identified in their 
overall trend, elastic stiffness and slip resistance level. Both curves are within the limit of the maximum upper bound DSM moment (shown by horizontal dotted lines) and, as desired, show no strength degradation which indicates the ductility capacity has been mainly provided through the bolts slip. This can be visualised through comparison of the deformed shape of the test and FE connections, as seen in Fig. 15, in which both show similar connection rotation through the bolts slip with no trace of local buckling in the beams at the very large deformation of $0.08 \mathrm{rad}$. A complete report of the conducted tests will be reported subsequently.

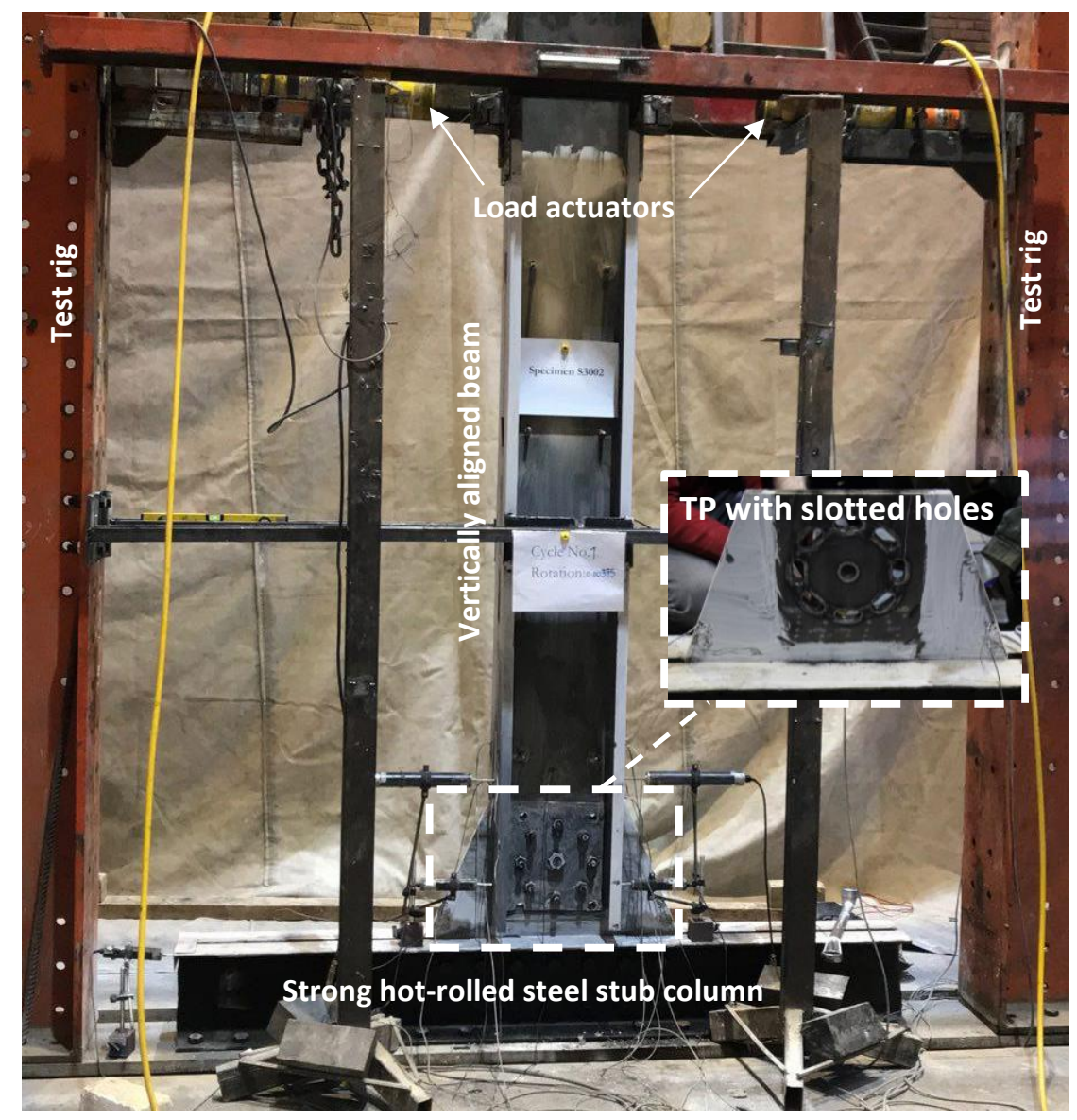

Figure 13. Overall view of a CB-connection vertically positioned in a test rig 


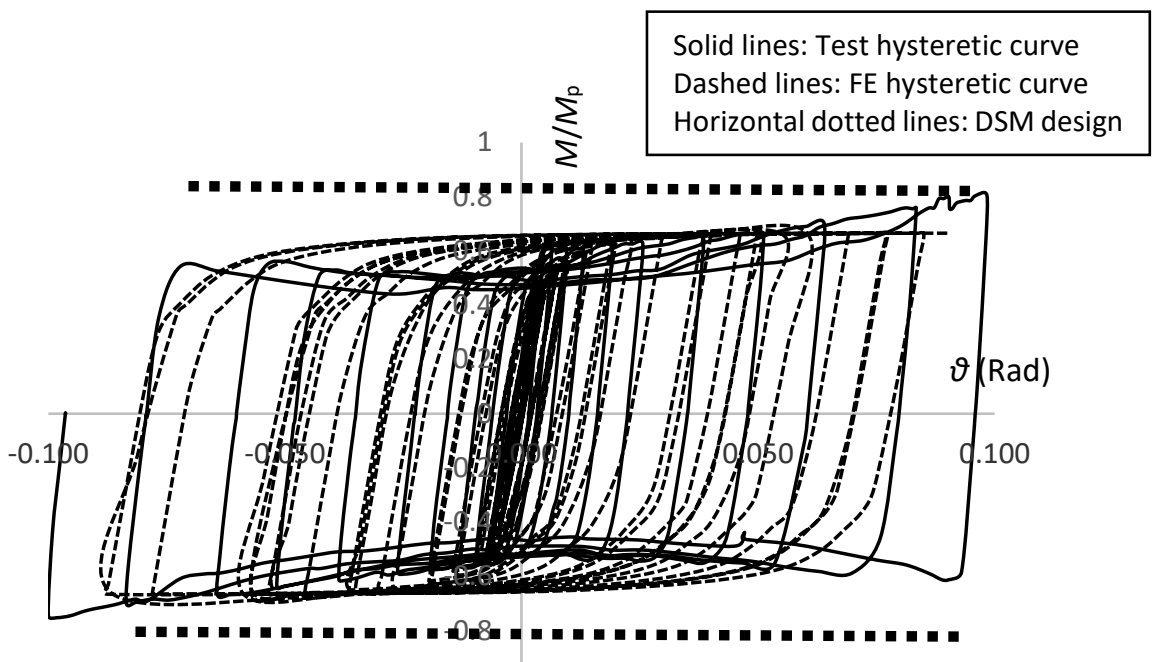

$-1$

Figure 14. FE and test hysteretic curves for the CB-connection with slip at $0.5 M_{\mathrm{p}}$ having $4 \mathrm{~mm}$ thickness $\mathrm{S}$ section beam
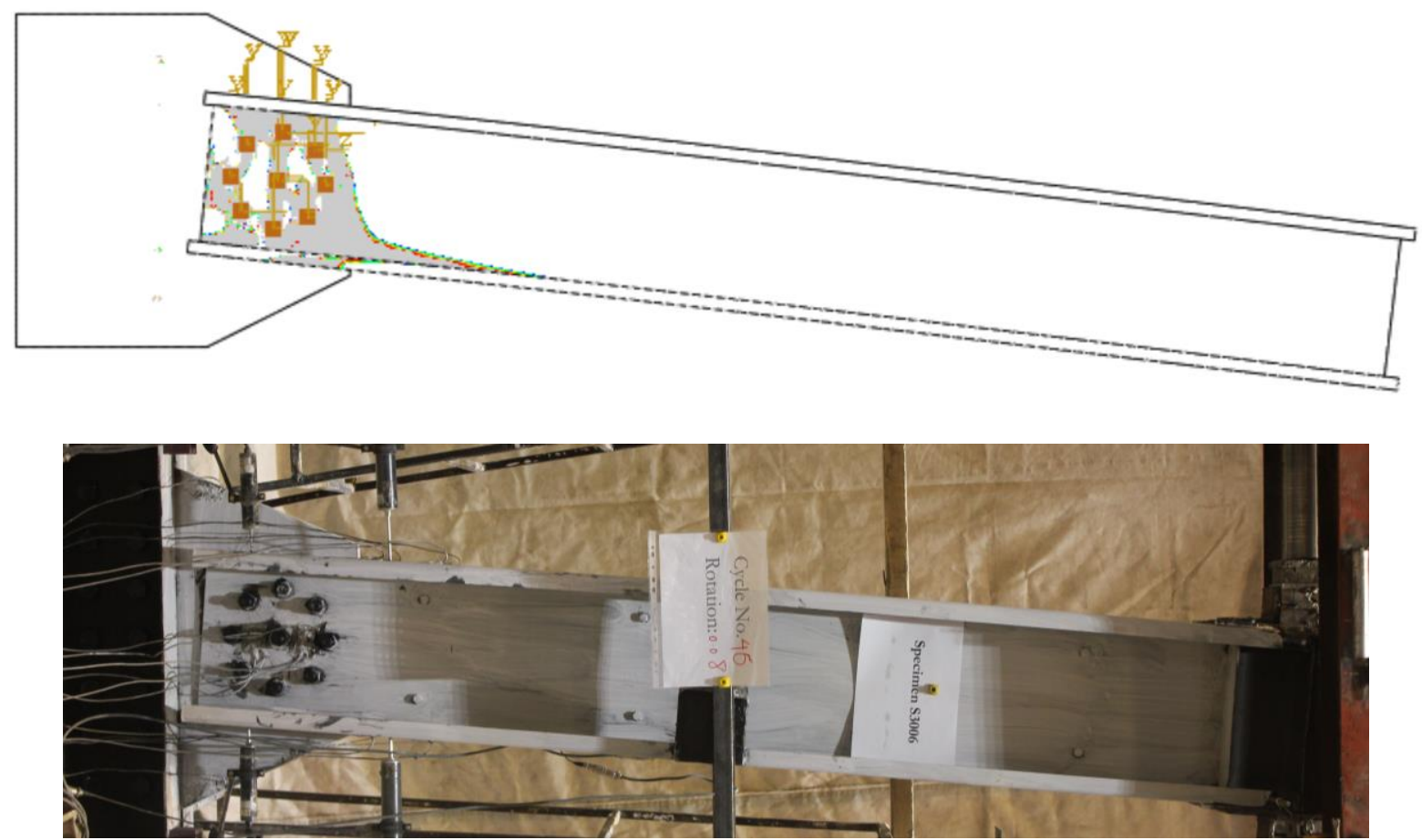

Figure 15. FE and test deformed shape at 0.08 rad rotation for the $\mathrm{CB}$-connection having $4 \mathrm{~mm}$ thickness $\mathrm{S}$ section beam with connection slip at $0.5 \mathrm{Mp}$ 


\section{Conclusions}

A comprehensive FE study was presented adopting bolting friction-slip mechanism to improve ductility and energy dissipation capacity of cold-formed steel (CFS) moment-resisting (MR) connections. Two types of square and circular bolting (SB and CB) arrangements were investigated, with different design bolt slip capacities chosen to give bolt slip at connection moment levels of $0.3 M_{p}, 0.5 M_{p}, 0.7 M_{p}$, for comparison with the connection without slip. The results showed that activation of the friction-slip mechanism can postpone beam local buckling and significantly improve ductility and energy dissipation capacity by up to $75 \%$ compared with that of the connection without slip. This was due to the elimination of the strength degradation and the slackening effect in the hysteretic curves.

To predict the connection slip moment to be initiated before the beam buckling, a design approach has been introduced using the direct strength method (DSM). A slip moment of less than one half of the buckling moment of the equivalent $F$ section has been shown to give a fairly reliable result. This was due to the unavoidable uncertainties in the bolt group force distribution and the deviation of the buckling moments from DSM compared with those obtained by FEA, particularly for the lower thickness beams with unqualified sections (according to the specifications in AISI S100 [17]).

The obtained moment-rotation curves and the bolt-group force distribution indicated that the $\mathrm{CB}$ connections provide a more uniform bolt behaviour than the SB connections, and, as a result, showed less tendency to excessive additional moment in the joint. Given that such excessive additional moment could introduce undesirable local buckling in the beam, with consequential loss of ductility, SB connections are not as reliable as the CB arrangement. It was also shown that, in general, the instantaneous centre of rotation (ICR) of the connections with slip are less deviated from the idealised centre of rotation compared with that of the connections without slip.

For validation purposes, the hysteretic moment-rotation curve and the connection slip deformed shape for a CB joint obtained using the FEA have shown a good agreement with those obtained through the corresponding tested joint.

Overall, it can be concluded that bolting friction-slip mechanism, if appropriately designed, can significantly improve ductility and energy dissipation capacity of CFS structures, in which local buckling inhibits their wider use, particularly in seismic areas.

\section{Appendix A. Bolts pre-tension forces}

Table A.1 presents the beam-to-TP bolts pre-tension forces (calculated based on EC 3 part 1.8 [7] design equations) for the investigated $\mathrm{CB}$ and $\mathrm{SB}$ connections having $300 \mathrm{~mm} \mathrm{~S}$ section beam with the 
bolt-group slip moments at $0.3 M_{p}, 0.5 M_{p}$ and $0.7 M_{p}$ using a class 8.8 bolt with the diameter of $d=20$ $\mathrm{mm}$ and slip factor of $\mu=0.3$.

Table A.1. The beam-to-TP bolts pre-tension forces with CB and SB connections having $300 \mathrm{~mm} \mathrm{~S}$ section beam

\begin{tabular}{|c|c|c|c|c|c|}
\hline \multirow{2}{*}{$\begin{array}{l}\text { S beam } \\
\text { thickness } \\
(\mathrm{mm})\end{array}$} & \multirow{2}{*}{$\begin{array}{l}\text { Bolt-group } \\
\text { slip level } \\
\left(M / M_{p}\right)\end{array}$} & $\begin{array}{l}\text { Pre-tension } \\
\text { force }(k N)\end{array}$ & $\begin{array}{c}\text { Slip force of } \\
\text { farthest bolts } \\
\text { from centre }(\mathrm{kN})\end{array}$ & $\begin{array}{l}\text { Pre-tension } \\
\text { force }(k N)\end{array}$ & $\begin{array}{c}\text { Slip force of } \\
\text { farthest bolts } \\
\text { from centre }(\mathrm{kN})\end{array}$ \\
\hline & & \multicolumn{2}{|c|}{ CB connection } & \multicolumn{2}{|c|}{ SB connection } \\
\hline \multirow{3}{*}{6} & 0.3 & 20 & 33 & 22 & 36 \\
\hline & 0.5 & 40 & 66 & 42 & 69 \\
\hline & 0.7 & 58 & 96 & 64 & 105 \\
\hline \multirow{3}{*}{4} & 0.3 & 17 & 28 & 19 & 32 \\
\hline & 0.5 & 26 & 43 & 29 & 47 \\
\hline & 0.7 & 38 & 63 & 41 & 68 \\
\hline \multirow{3}{*}{2} & 0.3 & 7 & 12 & 8 & 14 \\
\hline & 0.5 & 10 & 17 & 11 & 19 \\
\hline & 0.7 & 15 & 25 & 17 & 27 \\
\hline
\end{tabular}

\section{Appendix B. Mesh sensitivity analysis}

Fig. B1 shows the result of mesh sensitivity analysis for the $C B$ cantilever joint (shown in Fig. 4) having $4 \mathrm{~mm} \mathrm{C}$ section beam, with the connection slip initiated at $0.5 M_{\mathrm{p}}$; using mesh sizes of 5, 10, 15 and 20 $\mathrm{mm}$ for both the beam and the through plate components. As can be identified, the range of adopted mesh sizes have not meaningfully affected the overall elastic stiffness of the joints as also suggested by Schafer et al. [20]. The differences between the curves are noticeable in the post-yielding region for which, as expected, the joint with the finest mesh of $5 \mathrm{~mm}$ resulted in the most accurate behaviour. The $10 \mathrm{~mm}$ mesh size, however, was chosen given its reasonable accuracy and computational time consumption particularly for the hysteretic analysis part of the work.

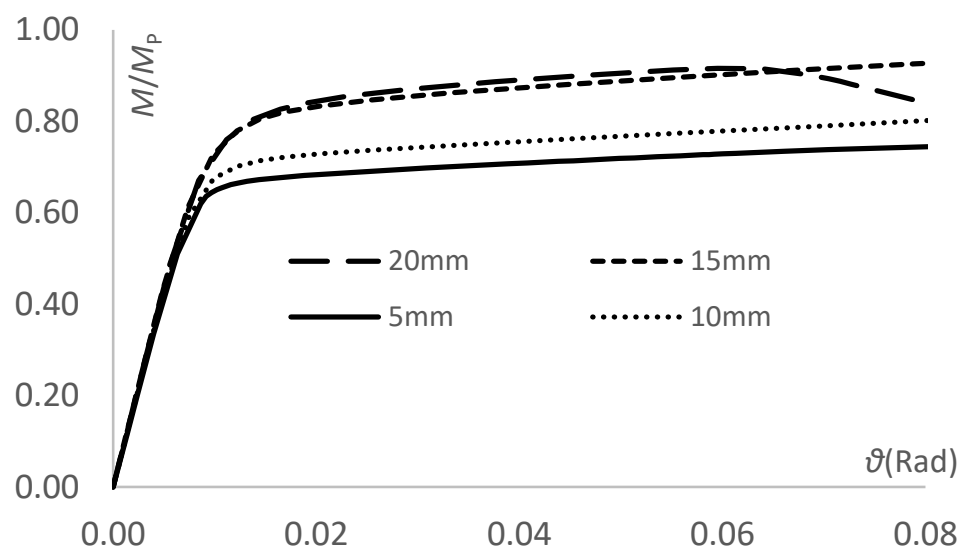

Figure B1. Mesh sensitivity analysis for the CB cantilever joint (shown in Fig. 4) having $4 \mathrm{~mm} \mathrm{C}$ section beam, with slip initiated at $0.5 \mathrm{Mp}$ 


\section{Appendix C. ICR calculation connections using standard method}

Fig.A1 illustrates a standard method to calculate the ICR of a CB connection under an eccentric shear load of $P_{i}$ which is applied in y direction. For bolt $i$, force components of $F_{\mathrm{mi}}$ (which is perpendicular to radius $r_{\mathrm{i}}$ ) and $F_{\mathrm{vi}}$ (in downward direction) are applied due to, respectively, bending moment at the centre of gravity (CG) and a uniformly distributed shear force between the bolts. The ICR is located where a line (shown by dashed lines in Fig.A1) perpendicular to the resultant force $\left(F_{R}\right)$ intersect the horizontal centre line of the bolts. A more general calculation of ICR can be found in [22].

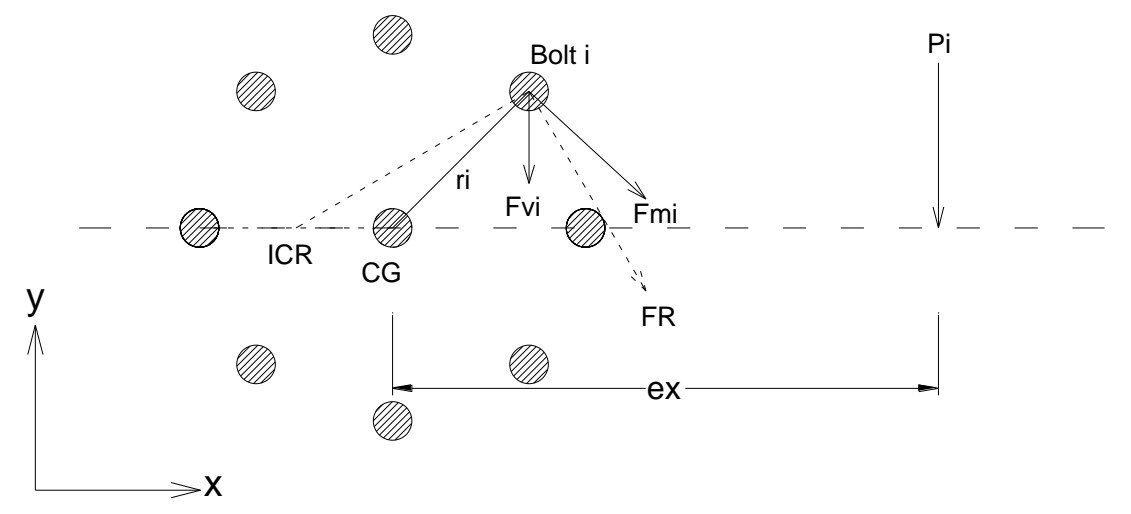

Figure C1. ICR calculation for a CB connection under a vertical shear force

\section{References}

[1] ANSI-AISI-S400-15. North American Standard for Seismic Design of Cold-Formed Steel Structural Systems. Washington, D.C.: American Iron and Steel Institute

[2] Moghimi H., Ronagh H. (2009), Performance of light-gauge cold-formed steel strap-braced stud walls subjected to cyclic loading, Engineering Structures, 31, 69-83.

[3] Bagheri Sabbagh A., Petkovski M., Pilakoutas K., Mirghaderi R. (2012), Experimental work on cold-formed steel elements for earthquake resilient moment frame buildings, Engineering Structures, 42, 371-386.

[4] Bagheri Sabbagh A., Petkovski M., Pilakoutas K., Mirghaderi R. (2011), "Ductile moment-resisting frames using cold-formed steel sections: An analytical investigation”, Journal of Constructional Steel Research, 634646.

[5] Bagheri Sabbagh A., Mihail Petkovski, Kypros Pilakoutas, Rasoul Mirghaderi (2012), Development of coldformed steel elements for earthquake resistant moment frame buildings, Thin-Walled Structures, 53, 99-108.

[6] Bagheri Sabbagh A., Petkovski M., Pilakoutas K., Mirghaderi R. (2013), Cyclic behaviour of bolted coldformed steel moment connections: FEM including slip, Journal of Constructional Steel Research, 80, 100-108

[7] Eurocode 3: design of steel structures: Part 1.8: Design of joints, EN 1993-1-8; 2005

[8] Eurocode 8: Design of structures for earthquake resistance. Part 1, General rules, seismic actions and rules for buildings. BS EN 1998-1: 2004

[9] ANSI/AISC 341-05 (2010), seismic provisions for structural steel buildings, American institute of steel construction (AISC), Illinois. 
[10] Sato A., Uang C-M (2009), Seismic design procedure development for cold-formed steel-special bolted moment frames. Journal of Constructional Steel Research, 65,860-868.

[11] Guide to Design Criteria for Bolted and Riveted Joints, (AISC Standard), 2001

[12] Uang C-M, Sato A., Hong J-K, Wood K. (2010). Cyclic testing and modeling of cold-formed steel special bolted moment frame connections. Journal of Structural Engineering, Vol. 136, No. 8, 953-960

[13] Lim J.B.P., Nethercot D.A. (2004). Stiffness prediction for bolted moment-connections between cold-formed steel members, Journal of Constructional Steel Research, 60, 85-107

[14] Lim J.B.P., Nethercot D.A. (2003). Ultimate strength of bolted moment-connections between cold-formed steel members, Thin-Walled Structures 41, 1019-1039

[15] Shu, Z., Ma, R., and He, M., Comprehending the ductile behavior of slotted bolted connections. Struct. Design Tall Spec. Build. 2017;26:e1309

[16] Abaqus Analysis User's Manual, (2010), version 6.14, United States of America.

[17] AISI-S100-12. North American Specification for the Design of Cold-Formed Steel Structural Members. Washington, D.C.: American Iron and Steel Institute; 2012.

[18] Li Z, Schafer BW (2010) "Buckling analysis of cold-formed steel members with general boundary conditions using CUFSM: conventional and constrained finite strip methods." Proceedings of the $20^{\text {th }}$ International Speciality Conference on Cold-Formed Steel Structures, St. Louis, MO.

[19] Lim J. B.P., Hancock G. J., Clifton G. C., Pham C. H., \& Das R. (2016). DSM for ultimate strength of bolted moment-connections between cold-formed steel channel members. Journal of Constructional Steel Research, 117, 196-203

[20] Schafer B.W., Li Z., Moen C.D. (2010). Computational modeling of cold-formed steel. Thin-Walled Structures, 48, 752-762

[21] Ye J., Mojtabaei S.M., Hajirasouliha I., Shepherd P. (2018). Strength and deflection behaviour of cold-formed steel back-to-back channels. Engineering Structures, 177, 641-654

[22] Structural Steel Work Connections, Graham W. Owens, Brian D. Cheal, 1982. 